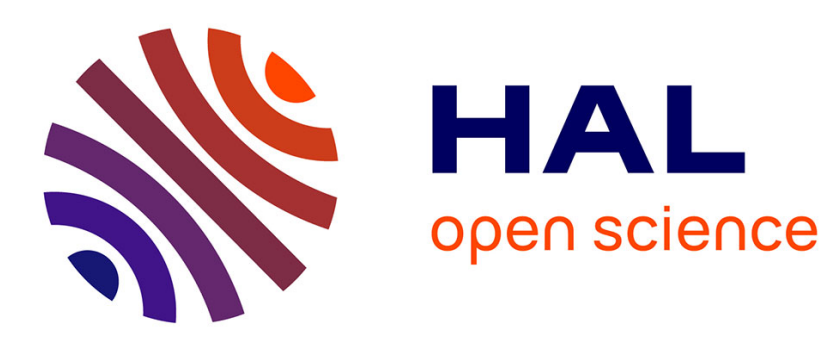

\title{
Influence of dissolution on long-term frictional properties of carbonate fault gouge
}

\author{
Hadrien Rattez, F. Disidoro, Jean Sulem, Manolis Veveakis
}

\section{To cite this version:}

Hadrien Rattez, F. Disidoro, Jean Sulem, Manolis Veveakis. Influence of dissolution on long-term frictional properties of carbonate fault gouge. Geomechanics for Energy and the Environment, In press, pp.100234. 10.1016/j.gete.2021.100234 . hal-03120086

\section{HAL Id: hal-03120086 \\ https://hal.science/hal-03120086}

Submitted on 25 Jan 2021

HAL is a multi-disciplinary open access archive for the deposit and dissemination of scientific research documents, whether they are published or not. The documents may come from teaching and research institutions in France or abroad, or from public or private research centers.
L'archive ouverte pluridisciplinaire HAL, est destinée au dépôt et à la diffusion de documents scientifiques de niveau recherche, publiés ou non, émanant des établissements d'enseignement et de recherche français ou étrangers, des laboratoires publics ou privés. 


\section{Influence of dissolution on long-term frictional properties of carbonate fault gouge}

3 H. Rattez ${ }^{1,4}$, F. Disidoro ${ }^{2}$, J. Sulem ${ }^{3}$, M. Veveakis ${ }^{1}$

$4 \quad{ }^{1}$ Duke University, Durham, North Carolina, USA.

$5 \quad{ }^{2}$ Politecnico di Torino, Turin, Italy.

$6 \quad{ }^{3}$ Laboratoire Navier, Ecole des Ponts ParisTech, UGE, CNRS, Champs-sur-Marne, France.

$7{ }^{4}$ Institute of Mechanics, Materials and Civil Engineering (IMMC), Université Catholique de

8 Louvain, B-1348 Louvain-la-Neuve, Belgium

9 Corresponding author: Hadrien Rattez (hadrien.rattez@duke.edu)

10 Key Points:

11 - Velocity stepping experiments have been conducted on a synthetic calcite gouge using an 12 annular shear apparatus to study the effect of the injection of an acid fluid on the long13 term frictional properties of the gouge.

14 - The dissolution process affects the particle size distribution of the gouge material and the 15 roughness of the particles.

- Experimental results show a decrease toward more negative values of the carbonate gouge Rate and State parameter (a-b) due to dissolution for experiments performed on dry specimens, whereas an increase of (a-b) is observed for wet experiments.

\section{Abstract}

21 Velocity stepping experiments have been performed on a simulated calcite gouge using an

22 annular shear apparatus to investigate the effect of dissolution on the frictional properties of a

23 carbonate fault. The tested material was put in contact with hydrochloric acid at different

24 concentration in order to provoke grains dissolution prior to the experiments. Particle size

25 analysis shows that the small grains tend to disappear due to the chemical reaction, whereas the 
distribution of large grains is not much affected. The dissolution process induces a decrease of

27 the fractal number of the grain size distribution and an increase of the roughness of the particles.

28 The study of the rate-and-state parameter of the materials, which is commonly used to 29 characterize the ability of the fault to generate earthquakes, shows a decrease toward more 30 negative values with dissolution for dry specimens and an increase for wet samples. Moreover, a 31 decrease of the steady state friction coefficient is observed with dissolution for wet samples. This 32 decrease of the friction would promote the triggering of slip along an existing fault after the 33 injection of an acid fluid like in the cases of $\mathrm{CO}_{2}$ storage or acid gas disposal projects in a 34 carbonate reservoir, but the increase of the rate and state parameter $(a-b)$ of saturated specimens 35 implies that the seismogenic potential of faults could potentially be reduced.

\section{Introduction}

A variety of human activities can modify the stress state or the material properties of underground rocks and, thus, induce potentially a frictional instability at the origin of an earthquake. Human-induced seismicity has been evidenced for a large range of activities (e.g., (Foulger et al. 2018)). Among them, the most commonly reported anthropogenic activities are mining and water reservoir impoundment, but it can also be caused by hydrofractures, oil and gas extraction, waste water disposal or geothermal projects (Wilson et al. 2017). Human-made seismicity have drastically increased in the U.S. since 2001 from a previous average of 21 earthquakes a year to 188 documented in 2011 (Ellsworth 2013). For instance, infrastructures and people in Oklahoma and southern Kansas face potential damages in the next years from induced earthquakes, in a similar level to regions known for their large number of natural earthquakes, like southern California (Schoenball and Ellsworth 2017).

Projects like carbon capture and storage, acid gas disposal or enhanced oil recovery involve the 49 injection of a reacting fluid into a reservoir (Khan, Amin, and Madden 2013). Carbon Capture 50 and Storage (CCS) is one of the methods considered to reduce emissions of $\mathrm{CO}_{2}$ into the 51 atmosphere (Espinoza 2011). The principle is to capture the $\mathrm{CO}_{2}$ and separate it from other gases 52 in the combustion smoke of large point sources like cement factories or coal-burning power 53 plants. Once extracted, the gas is compressed and transported with a pipeline to injection sites for 54 long term storage. Acid gas disposal is a method used by oil and gas producer to reduce 55 atmospheric emissions of hydrogen sulphide $\left(\mathrm{H}_{2} \mathrm{~S}\right)$. A mixture of hydrogen sulphide and carbon 
dioxide (by-product of 'sweetening' sour hydrocarbons) is injected into depleted reservoirs or

57 deep saline aquifers (Bachu and Gunter 2004). Enhanced oil recovery, also called tertiary recovery, is a way to improve the extraction of crude oil from reservoir that could not be extracted otherwise (Rubinstein and Mahani 2015). The most common methods are gas or chemical injection that modify the viscosity of the oil and improve its mobility. In these cases, induced seismicity could produce damage to the well or the caprock and deteriorate the sealing of the reservoirs, leading to the failure of the project.

A large number of numerical studies have been devoted to study the mechanisms at the origin of induced seismicity and to evaluate the maximum magnitude of the earthquake a project may induce (e.g. Cappa 2012). Most of them consider a hydro-mechanical model and look at the modifications of the stress state at the location of a known fault in a specific site (Baisch et al. 2010; Yehya, Yang, and Rice 2018; Mortezaei and Vahedifard 2015; Cappa 2012). In these studies, fluid injection into a reservoir-caprock system bounded by a fault is modelled with different stress state conditions and assuming various permeability conditions. The stress modifications induced by the fluid potentially leading to an earthquake can be computed and the value of the stress drop permits to estimate the magnitude.

72 The injection of an acid fluid does not only change the stress state, but also modifies the 73 properties of the storage medium and can, in particular, affect the mechanical behavior of fault zones. Due to the conditions of stresses, temperature and velocity, many complex couplings are involved in earthquake nucleation and propagation (Rice 2006; Sulem and Famin 2009; Alevizos, Poulet, and Veveakis 2014; Veveakis, Poulet, and Alevizos 2014; Rattez and Veveakis 2020). In fault reactivation simulations based on effective stresses modifications, reactivation through a possible decrease in the frictional strength of fault zones is usually not taken into account. However, experimental studies have looked at the influence of physico-chemical interactions on the potential of a fault to create earthquakes (see (Rohmer, Pluymakers, and Renard 2016) for a review in the context of $\mathrm{CO}_{2}$ storage). The largest impact of the injection of a

82 reacting fluid on the mechanical properties has been observed for carbonate reservoirs (Rohmer,

83 Pluymakers, and Renard 2016), which are potential target formations for $\mathrm{CO}_{2}$ capture and

84 storage (Michael et al. 2010). Some experiments have looked at the influence of the short term

85 effect of the presence of $\mathrm{CO}_{2}$-saturated water on the value of the friction coefficient (Samuelson 86 and Spiers 2012; Anne M H Pluymakers et al. 2014) or the velocity dependence of the friction 
87 coefficient (Samuelson and Spiers 2012; Rattez, Sulem, and Ghabezloo 2014; A. M.H.

88 Pluymakers, Niemeijer, and Spiers 2016a), which is of primary importance for earthquake 89 nucleation. To our knowledge, the only experimental study on the long-term effect of a contact 90 with an acidic fluid is (Bakker 2017) by modifying the gouge content and the fraction of the 91 different minerals based on chemical calculations.

92 In this work, we perform experiments on analog carbonate fault gouges previously subjected to 93 different degrees of dissolution at different normal stresses. The aim is to assess the effect of 94 long-term exposure to an acidic fluid on frictional properties of a carbonate material (section 3). 95 Carbonate materials are chosen here as many reservoirs and potential sites for injection of $\mathrm{CO}_{2}$ 96 storage or acid gas disposal are carbonate formations (Bjorlykke 2010). The mechanical results 97 obtained from annular shear experiments on dry and wet specimens and microstructural 98 observations are used to infer the micro-physical processes controlling frictional sliding of 99 calcite fault gouges and discuss the potential effect of dissolution on fault's reactivation (section 100 4).

101 2. Experimental setup

102 2.1. Materials

103 The material used for the experiments is a carbonate rock powder extracted from the Fergues 104 quarry by the company "les Carrières du Boulonnais" located in the North of France. The 105 powder is produced by crushing of rocks from the quarry and is composed of $99 \%$ of calcite $106\left(\mathrm{CaCO}_{3}\right)$ and show traces of quartz $\left(\mathrm{SiO}_{2}\right)$, magnesium carbonate $\left(\mathrm{MgCO}_{3}\right)$, Hematite $\left(\mathrm{Fe}_{2} \mathrm{O}_{3}\right)$ 107 and Aluminum Oxide $\left(\mathrm{Al}_{2} \mathrm{O}_{3}\right)$. The grain size distribution is obtained using a combination of 108 sieves and hydrometer analysis or laser diffraction. Both methods show similar results and the 109 broad grain size distribution of the material is shown in Figure 1.

110 To study the effect of dissolution, granular samples are placed in a large plastic container with a 111 certain amount of water and then, a solution of hydrochloric acid (mass concentration of 10\%) is 112 slowly poured. In the meantime, the solution is stirred with an electric mixer to obtain a uniform 113 dissolution in the sample. Hydrochloric acid is a strong acid and is used here to simulate the 114 long-term effect of dissolution by a weak acid like carbonic acid on the grain size distribution. 115 The reason for using this acid, instead of carbonic acid or other acids, corresponding to the fluid 116 injected in the case of acid gas injection or enhanced oil recovery, is that the kinetics of the 
117 chemical reaction is almost instantaneous. The calcium carbonate $\left(\mathrm{CaCO}_{3}\right)$ is dissolved by the 118 hydrochloric acid $(\mathrm{HCl})$ and the products of reaction are carbon dioxide $\left(\mathrm{CO}_{2}\right)$, water $\left(\mathrm{H}_{2} \mathrm{O}\right)$ and 119 calcium chloride $\left(\mathrm{CaCl}_{2}\right)$ (Lund et al. 1975). The equation of the chemical reaction is:

$$
\mathrm{CaCO}_{3}^{(\mathrm{s})}+2 \mathrm{HCl}^{(\mathrm{l})} \rightarrow \mathrm{CaCl}_{2}^{(\mathrm{aq})}+\mathrm{H}_{2} \mathrm{O}^{(\mathrm{l})}+\mathrm{CO}_{2}^{(\mathrm{g})}
$$

$120 \mathrm{CaCl}_{2}$ is highly soluble (Kirk-Othmer 2004) and the specimens put in contact with the acid are 121 then washed several times with water after the end of the reaction to ensure that this product is 122 removed. The degrees of degradation chosen for this study are $10 \%$ and $25 \%$ weight percentages 123 of material that is dissolved from the acid during the reaction. The software ChemDigiT is used 124 to calculate the exact quantity of hydrochloric acid required to dissolve the various amounts of 125 materials. Considering that the software provides the amount of pure hydrochloric acid (no 126 dilution with water), while the solution at our disposal had a concentration of $23 \%$ in weight 127 (100 g of solution: $23 \mathrm{~g}$ of $\mathrm{HCl}+77 \mathrm{~g}$ of $\mathrm{H}_{2} \mathrm{O}$ ), we have scaled the provided quantities as 128 function of this concentration. The amount of water initially placed in the container with the rock 129 powder is calculated for the hydrochloric solution to not exceed $10 \%$ in weight.

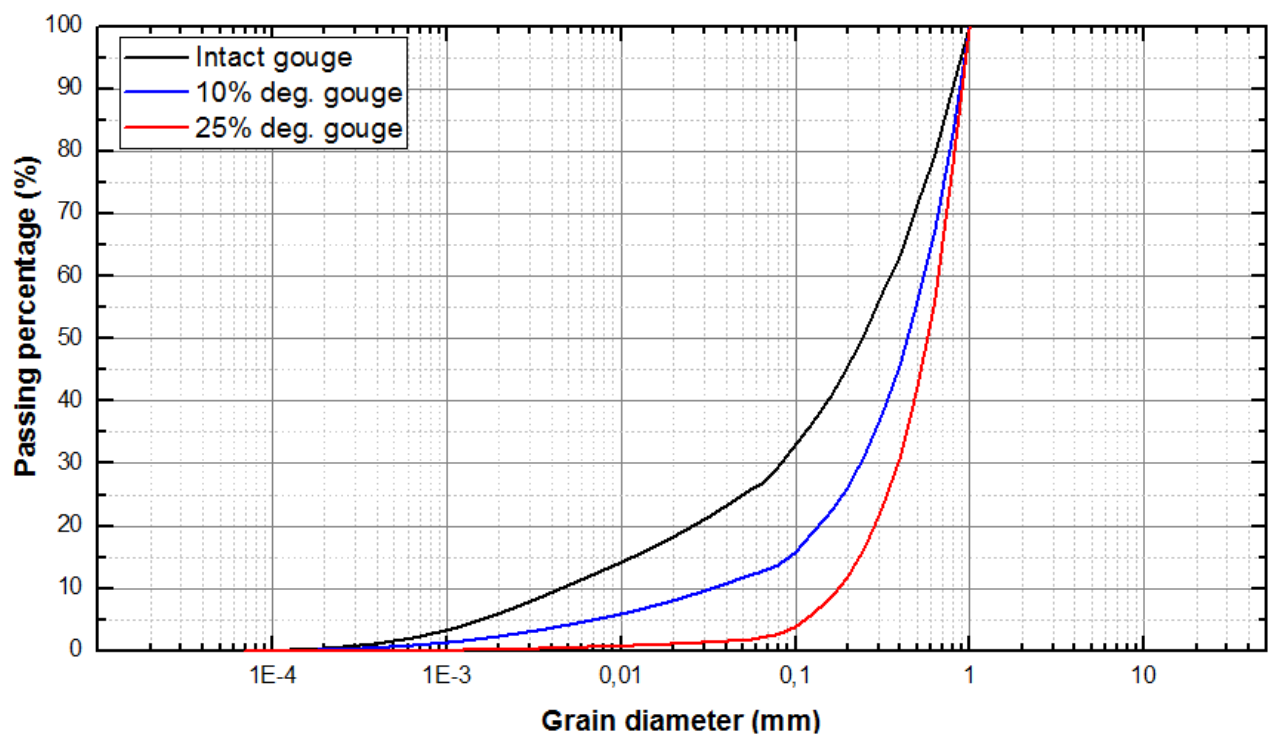

134 The cumulative grain size distributions of the samples for the initial material, after $10 \%$ and $25 \%$ 135 of dissolution of the total mass are shown in Figure 1. In particular, the higher the degradation, 
136 the more the small particles get dissolved. This phenomenon is due to the greater specific surface 137 that small particles offer to the reactive fluid compared to bigger particles.

138 Considering that our tests are carried out on a material that is supposed to simulate a natural fault 139 gouge, one of the most important material properties to be assessed is the fractal dimension of 140 the grain size distribution. The fractal dimension $(D)$ is defined by $141 N=r^{D}$, where $N$ is number of particle of diameter $r$. (Sammis, King, and Biegel 1987) 142 measured the particle distribution of intact gouge samples retrieved from the Lopez Fault in the 143 San Gabriel Mountains of Southern California. The gouge is composed mainly of feldspars, 144 quartz and chlorite, with smaller amounts of calcite and other oxides. The analysis has revealed a 145 remarkable degree of self-similarity for the grain size distribution and the authors have found the 146 fractal dimension to be $1.60 \pm 0.11$ in two-dimensional cross-section. Thus, the fractal dimension 147 is $2.60 \pm 0.11$ in a three-dimensional volume as a general result of fractal theory states that the 148 fractal dimension of an isotropic three-dimensional figure is greater by unity than a two149 dimensional cross-section of it (Sammis, King, and Biegel 1987). On the basis of the 150 observations, they proposed a new model, called the comminution model, for the mechanical 151 processes that generate fault gouges. Self-similarity results from repeated tensile splitting of 152 grains and that splitting probability depends largely on the relative size of nearest neighbors: 153 during the fragmentation process, the direct contact between two particles of near equal size will 154 result in the tensile breakup of one of the two. In this way, at the end of fragmentation process, 155 the material will have a particle distribution in which particles of the same size are separated 156 from each other. Such a spatial organization repeats itself at each scale, providing a self-similar 157 grain size distribution having a fractal dimension of 2.58, independently of the initial size 158 distribution of the particles. After the development of this model, several authors conducted 159 experiments on natural and simulated fault gouges, showing their tendency to develop a fractal 160 dimension values of about 2.6 supporting the Sammis' theory (Steacy and Sammis 1991; An and 161 Sammis 1994). Moreover, (Biegel, Sammis, and Dieterich 1989) have investigated the frictional 162 properties of gouge presenting fractal dimension of 2.6 and in particular the role of the minimum 163 and maximum grain size. However, (Storti, Billi, and Salvini 2003) have analyzed gouge 164 samples of a carbonate fault in the Apennines, Italy and have shown that for this material the 165 comminution model is not always verified. Fractal dimensions obtained from fault cores varies 166 from 2.61 to 3.49 in strike-slip faults' gouge and between 2.17 to 2.74 in the breccia zones. They 
167 recognized the value 2.6 to be a threshold between a first stage of fault gouge formation 168 dominated by particles fragmentation and a second one dominated by particles abrasion in the 169 case of carbonate materials.

170 In Figure 2, the number of particles as a function of the grain diameter is shown for the different 171 level of dissolution of the grains. The value of the fractal number of the simulated gouge that is 172 not dissolved (intact) is in agreement with the comminution theory and this material can, 173 therefore, be considered as a good analog of a gouge material at the first stage of formation. The 174 dissolution induces a decrease of the fractal number from 2.59 to 2.16. This decrease is due to 175 the preferential dissolution of the small particles from the grain size distribution, in the same way 176 that abrasion makes the fractal number increase due to the creation of more small particles. An 177 interesting feature of the effect of dissolution on the particle size distribution is that it induces an 178 increase of the mean grain diameter. It can, thus, affect the prediction of continuum models 179 considering the mean grain size explicitly into the constitutive laws. These class of models are 180 used in particular to regularize the problem of strain localization like Cosserat continua (Rattez, 181 Stefanou, Veveakis, et al. 2018).

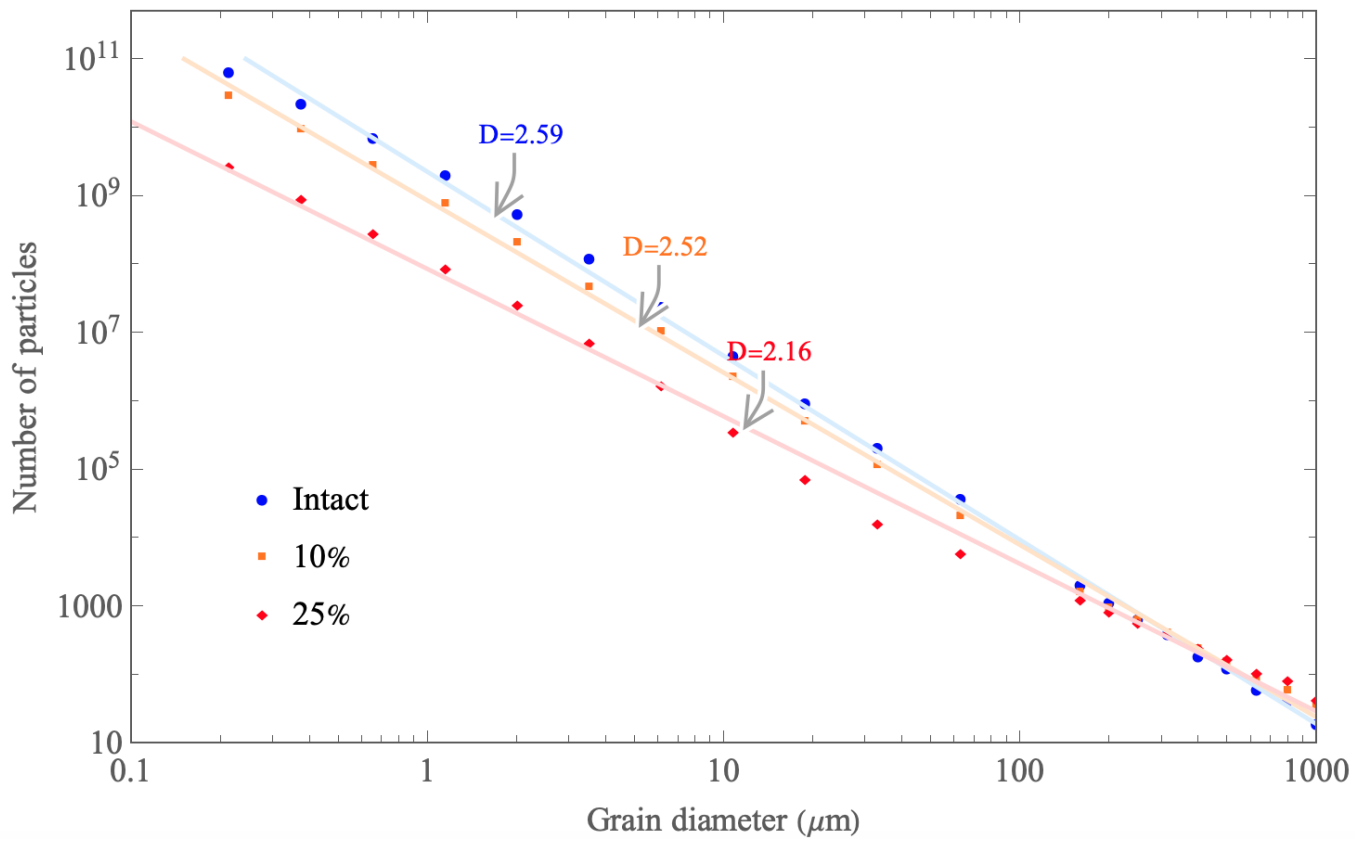

183 Figure 2. Number of particles as function of the grain diameter for different level of dissolution of the carbonate rock powder. 184 The points represent the experimental data obtained from sieve and hydrometer analyses. The lines represent an interpolation of 185 the experimental data using a power law. The fractal number associated $D$ with each distribution is also shown.

\subsection{Experimental set-up}


187 The device used for the mechanical tests is an annular simple shear device called ACSA 188 ("Appareil de Cisaillement Simple Annulaire”), designed in 1993 in the CERMES laboratory of 189 Ecole des Ponts (Unterreiner et al. 1993). It has been used in the context of fault mechanics by 190 (Guillaume Chambon, Schmittbuhl, and Corfdir 2006a, 2006b; Messen, Corfdir, and 191 Schmittbuhl 2013). This device enables to shear the gouge material over large displacements and 192 with samples that are thicker than other experimental devices. This thickness of the samples $193(10 \mathrm{~cm})$ represents an average value of the fault core thickness measured on outcrops of carbonate 194 rocks (Billi 2005; Torabi, Johannessen, and Ellingsen 2019). A schematic view of the machine is 195 shown in Figure 3. We only present here this apparatus briefly. A more detailed description can 196 be obtained from (Guillaume Chambon 2003; Corfdir, Lerat, and Vardoulakis 2004).

197 The internal surface of a ring-shaped sample, which presents a square section of $100 * 100 \mathrm{~mm}^{2}$, is 198 sheared by the rotation of a rough steel cylinder. A 15-bit optoelectronic rotation encoder is used 199 to monitor the rotation angle $\phi$ of the steel cylinder providing a $0.011^{\circ}$ resolution. The tangential 200 displacement $\delta$ at the inner boundary of the sample is deducted as $\delta=\phi \cdot R_{i}$ (where $R_{i}$ is the inner 201 radius of the sample) and is measured with a resolution of $1.9210^{-5} \mathrm{~m}$. The spacing between the 202 vertical triangular striation of the inner interface is $1 \mathrm{~mm}$, the same size as the maximum grain 203 diameter of the samples, in order to preclude interfacial slip along the steel-granular boundary 204 (Koval et al. 2011). The outer boundary of the sample is subjected to a constant radial 205 confinement $\sigma_{e}$ through a 1.5 -mm-thick neoprene jacket and applied using water by a pressure206 volume controller (max. press: $2 \mathrm{MPa}$, vol.: $10^{-3} \mathrm{~m}^{3}$, resolution: $1 \mathrm{kPa}$ and $1 \mathrm{~mm}^{3}$, accuracy $207<0.25$ per cent). Vertically, the sample is embedded between an upper plate made of duralumin 208 and a lower plate made of glass. 
a

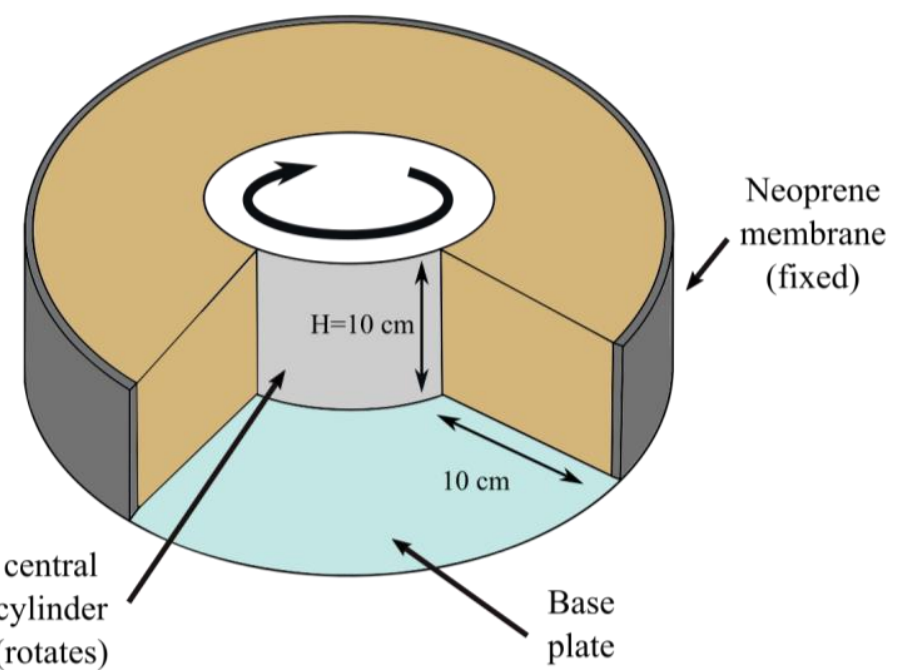

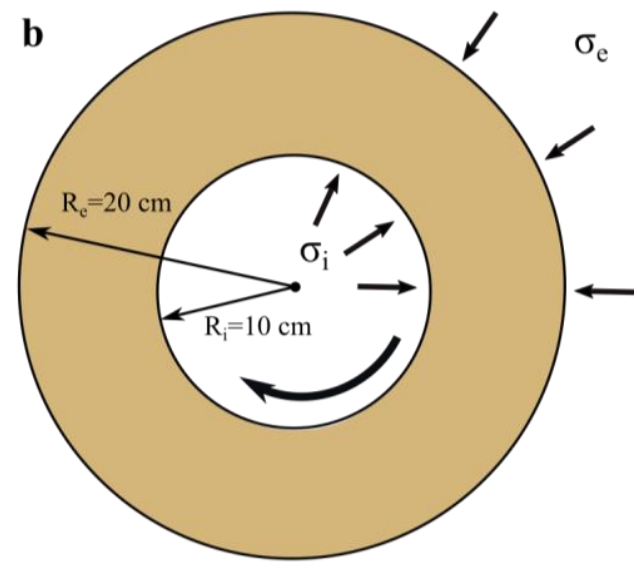

Figure 3. Schematic view of ACSA: a, Cut away view, $b$, top view

For a given normal stress, the samples are initially sheared at a constant speed of $33 \mu \mathrm{m} / \mathrm{s}$ for 10 $\mathrm{cm}$, in order to reach the steady-state friction coefficient. Then, the shearing velocity is instantaneously changed every $2 \mathrm{~mm}$ of slip to apply different velocity steps. The sequence shown in Table 1 is chosen such that each velocity step is repeated at least twice to better constrain the value of the friction parameters calculated. At the end of this phase, the shear force is unloaded, normal stress is increased and the procedure is repeated as in (Scuderi et al. 2013; Berend A. Verberne et al. 2015). It should be noted that the different normal stresses applied on the sample in this case also correspond to different applied displacements to the sample, which could affect the mechanical behavior.

\begin{tabular}{cccccccccc}
\hline Stage & $\mathbf{1}$ & $\mathbf{2}$ & $\mathbf{3}$ & $\mathbf{4}$ & $\mathbf{5}$ & $\mathbf{6}$ & $\mathbf{7}$ & $\mathbf{8}$ & $\mathbf{9}$ \\
\hline Displacement $[\mathbf{m m}]$ & 100 & 2 & 2 & 2 & 2 & 2 & 2 & 2 & 2 \\
\hline Speed $[\boldsymbol{\mu m} / \mathbf{s}]$ & 33 & 10 & 1.7 & 10 & 33 & 10 & 1.7 & 10 & 33 \\
\hline Table 1. Velocity stepping sequence applied to the sample for a given normal stress.
\end{tabular}

In Table 2, a list of all the conducted tests with different degrees of dissolution, different stages consisting of various normal stresses and conditions of saturation is presented. The "dry" experiments have been conducted in nominally dry conditions, that is with room atmosphere inside the pore space, while the "wet" experiments are conducted on specimens that are saturated with deaerated water and tested in drained conditions. We note that the samples were saturated in two steps: the water was first injected from the bottom of the specimen until the water level reached the valves located at the top, then the flow through the specimen was maintained until 
228 half the total volume of pore space of the specimen was expelled at the top, to ensure conditions 229 close to homogeneous saturation.

\begin{tabular}{cccc}
\hline Degradation & $\boldsymbol{\sigma}_{\boldsymbol{i}}(\mathbf{M P a})$ & saturation & Set of data name \\
\hline none & 0.6 & dry & Intact0.6 \\
\hline none & 1 & dry & Intact1 \\
\hline none & 1.6 & dry & Intact 1.6 \\
\hline $\mathbf{1 0 \%}$ & 0.6 & dry & $10 \mathrm{deg} 0.6$ \\
\hline $\mathbf{1 0 \%}$ & 1 & dry & $10 \mathrm{deg} 1$ \\
\hline $\mathbf{1 0 \%}$ & 1.6 & dry & $10 \mathrm{deg} 1.6$ \\
\hline $\mathbf{2 5 \%}$ & 0.6 & dry & $25 \operatorname{deg} 0.6$ \\
\hline $\mathbf{2 5 \%}$ & 1 & dry & $25 \mathrm{deg} 1$ \\
\hline none & 0.6 & wet & Intact0.6w \\
\hline none & 1 & wet & Intact1w \\
\hline none & 1.6 & wet & Intact $1.6 \mathrm{w}$ \\
\hline $\mathbf{1 0 \%}$ & 0.6 & wet & $10 \operatorname{deg} 0.6 \mathrm{w}$ \\
\hline $\mathbf{1 0 \%}$ & 1 & wet & $10 \mathrm{deg} 1 \mathrm{w}$ \\
\hline $\mathbf{1 0 \%}$ & 1.6 & wet & $10 \mathrm{deg} 1.6 \mathrm{w}$ \\
\hline $\mathbf{2 5 \%}$ & 0.6 & wet & $25 \mathrm{deg} 0.6 \mathrm{w}$ \\
\hline $\mathbf{2 5 \%}$ & 1 & wet & $25 \operatorname{deg} 1 \mathrm{w}$ \\
\hline $\mathbf{2 5 \%}$ & 1.6 & wet & $25 \operatorname{deg} 1.6 \mathrm{w}$ \\
\hline
\end{tabular}

Table 2 - List of complete set of phases and experiments

\subsection{Data acquisition and processing}

232 The apparent friction coefficient $\mu$ of the sample is calculated as the ratio of the applied shear

233 stress $\tau$ to the normal stress $\sigma, \mu=\frac{\tau}{\sigma}$. The shear stress $\tau$ can be found converting the applied 234 torque measurements $\Gamma$, measured by a torquemeter of 20 N.m accuracy:

$$
\tau=\frac{\Gamma / r}{2 \pi r H}=\frac{\Gamma}{2 \pi r^{2} H} \#(1)
$$

235 where $r$ and $H$ are respectively the radius and the height of the inner cylinder and are both equal 236 to $10 \mathrm{~cm}$. The normal stress exerted on the inner cylinder is different from the external normal 237 stress applied on the outer boundary of the sample due to the particular geometry of the sample. 238 According to (Guillaume Chambon 2003), simple geometrical considerations indicate that the 239 inner normal stress $\sigma_{i}$ should be equal to twice the applied confinement $\sigma_{\mathrm{e}}$, since the external 240 radius of the sample is the double of the internal one; moreover, the same authors conducted 241 some experiments equipping both the smooth and the rough cylinder with five stress sensors, and 
242 they found that normal stress on cylinders' surface was strongly varying at the beginning of the

243 test, but it tended to stabilize after few millimeters of slip toward values very close to the double

244 of external pressure. As the shear band is developing near the inner cylinder, the apparent

245 friction is calculated as:

$$
\mu=\frac{\tau}{\sigma_{i}}=\frac{\Gamma}{2 \pi r^{2} H} \cdot \frac{1}{2 \sigma_{e}} \#(2)
$$

\subsection{The Rate-and-State Friction (RSF) law}

247 (Reid 1910) was the first to argue after the 1906 San Francisco earthquake that this phenomenon 248 is not created by the emergence of a new crack in the crust, but rather by the sudden slip along an 249 existing fault. After the beginning of slipping the fault can move aseismically or seismically 250 (Scholz 1998) if a frictional instability is triggered. An empirical law describing the instability 251 along a fault was developed during the eighties by Dieterich and Ruina (Dieterich 1981; Ruina 252 1983). They introduced new state variables that describe a second order effect on the coefficient 253 of friction. These laws are called "Rate and State", because the friction depends on the velocity 254 of slipping (Rate) and a state variable $\theta$, which is interpreted as the average lifespan of a set of 255 grain-to-grain contacts in a frictional system. They describe the evolution of the friction 256 coefficient to changes in sliding motions by the equation:

$$
\mu=\mu_{0}+a \ln \left(\frac{V}{V_{0}}\right)+b \ln \left(\frac{V_{0} \theta}{D_{c}}\right) \#(3)
$$

$257 \mu_{0}$ is a reference friction coefficient, $V$ and $V_{0}$ are respectively the actual and reference velocities 258 of the fault. $D_{c}$ is the critical slip distance representing the slip necessary to renew contacts, 259 associated with the state variable $\theta$ (Marone 1998). $a$ and $b$ are empirical parameters. The 260 observed evolution of the state variable can be described by the following equation (Dieterich 261 1979):

$$
\frac{d \theta}{d t}=1-\frac{v \theta}{D_{C}} \#(4)
$$

262 These empirical laws can capture the repetitive stick-slip failure at the origin of the seismic 263 cycle. A simple system called the spring-slider model, in which the slider follows the rate and 264 state friction laws and the spring represents the elastic surrounding mass of the fault, is usually 265 applied to model seismic slips. The study of the linear stability of that system (Rice and Ruina 
266 1983) shows a critical value for the stiffness of the spring $k_{c r}$ (if the inertial terms are 267 negligible). Under this value, the system is unstable and over this value, it is conditionally stable.

$$
k_{c r}=\frac{\sigma_{N}}{D_{c}}(b-a) \#(5)
$$

268 where $\sigma_{N}$ is the effective normal stress applied perpendicular to the direction of sliding. 269 The parameter $(a-b)$ is therefore fundamental to determine the stability of a fault modelled 270 with a rate and state friction law, because if it is positive, frictional instability would not nucleate 271 with this model. Moreover, a modification of the value of (a-b) in the velocity-weakening regime 272 modifies the value of the critical stiffness and, if ( $a-b)$ becomes more negative (stronger 273 weakening), it can lead to seismic slips for faults that were stable before the modification.

274 The parameter $(a-b)$ can be calculated based on the values of the steady-state friction before 275 and after an instantaneous velocity change. At steady-state $(d \theta / d t=0)$ and the state evolution 276 law gives $\theta=D_{C} / v$. So, equation (3) becomes:

$$
\mu=\mu_{0}+(a-b) \ln \frac{v}{v_{0}} \#(6)
$$

277 To evaluate the friction parameter $(a-b)$, the general long-term strain trend of the apparent 278 friction is removed in order to avoid this factor to influence the $(a-b)$ values. It is typically a 279 softening trend as the one shown in Figure 4. The same procedure was also applied by several 280 studies (Blanpied, Lockner, and Byerlee 1995; Tembe, Lockner, and Wong 2010; Samuelson and 281 Spiers 2012) for velocity stepping experiments. 


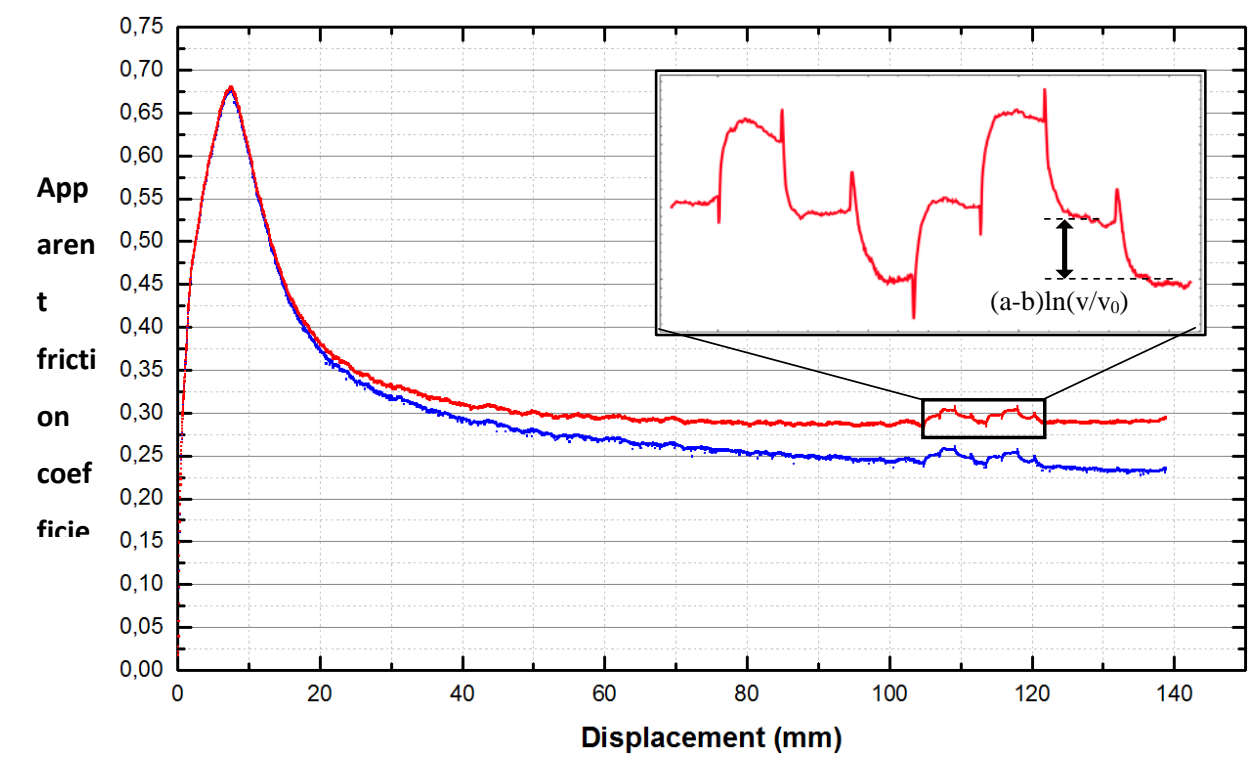

Displacement $(\mathrm{mm})$

284 The $(a-b)$ value of each velocity step can be obtained from the detrended evolution of the friction coefficient, and in particular, from the value of residual friction before the velocity change and the one obtained once a new steady state is obtained after the change:

$$
(a-b)=\frac{\mu_{0}-\mu}{\ln \left(V / V_{0}\right)} \#(7)
$$

287 where $\mu$ is the coefficient of friction at the end of a step with velocity $V$, and $\mu_{0}$ and $V_{0}$ are the 288 coefficient of friction and velocity immediately prior to the velocity step.

\section{Results}

290 In this section, we describe first the frictional data obtained from the mechanical experiments. 291 The global evolution of the apparent friction as well as the rate and state parameter $(a-b)$ are 292 presented together with their evolution with normal stress and dissolution rate. Secondly, the 293 specific surface areas of the samples are assessed by two methods in order to estimate the 294 rugosity of the grains. This analysis is completed with observations obtained using a scanning 295 electron microscope to interpret the different mechanical responses of the samples.

\subsection{Mechanical results}

297 An example of the apparent friction coefficient evolution with shear displacement is shown in 298 Figure 4. It exhibits a peak for a value between 0.6 and 0.7 for all dry experiments at $600 \mathrm{kPa}$ of 299 imposed normal stress. The peak is more pronounced for a normal stress of $600 \mathrm{kPa}$ as it is the 
300 first run applied to the material. This peak is followed by a slip-weakening behavior with a 301 characteristic slip distance of a few centimeters, also observed in the experiments performed on 302 glass beads and quartz sand by (Guillaume Chambon, Schmittbuhl, and Corfdir 2006a). The 303 evolution of the shear stress for all the stages of the experiments is shown in Figure 5 for the 304 different samples. The peak stress is less important for the normal stresses 1 and 1.6 MPa than 305 for $600 \mathrm{kPa}$ due to the multi-stage procedure.

306 We observe through the glass window at the bottom of the sample a strain localization of the 307 deformation next to the inner cylinders. The shear band thickness is on the order of a few 308 millimeters, which corresponds approximately to 10 times the mean grain size, in accordance 309 with results of numerical simulations of continuum models of granular media (Rattez, Stefanou, 310 Sulem, et al. 2018; Rattez, Stefanou, and Sulem 2018). However, digital image correlation needs 311 to be used to observe accurately the evolution of the thickness with increasing displacements as 312 in (G. Chambon et al. 2003) but has not been carried out for this study.

313 The value of the friction $\mu$ is not much affected by the dissolution in the dry case (see Figure 5 314 and Table 3), except for the residual friction at 1.6 MPa of normal stress. We can see that for the 315 tests performed under $600 \mathrm{kPa}$ of normal stress, the three peak values are nearly the same $316(\mu=0.63-0.67)$, as well as the residual values $(\mu=0.22-0.25)$. The same happens in the tests under $3171 \mathrm{MPa}$ of normal stress where the peak is exactly the same and the intact residual value is only a 318 bit higher that the degraded ones $(\mu=0.20)$. Finally, the 1.6 MPa run exhibits only a difference in 319 the value of the residual friction. In the wet experiments, the peak values and the residual friction 320 coefficients show a decrease with the dissolution (except the peak stress between the intact and 321 deg10 for the $600 \mathrm{kPa}$, which can be due to different degrees of initial compaction) for all normal 322 stresses. For the wet experiments, the residual friction decreases from $\mu=0.27-0.33$ for the intact 323 gouge to $\mu=0.14-0.15$ for the gouge dissolved at $25 \%$.

324 Regarding the velocity stepping experiments, the results presented in Figure 6 and Figure 7 show 325 that all of the tests performed in this study, regardless of degradation level and pressure, exhibit a 326 velocity weakening behavior. The $(a-b)$ values are falling between -0.003 and -0.018 ; the only 327 exception is the $25 \mathrm{deg} 0.6 \mathrm{dry}$ test (see Table 2 for the denomination of the tests), which exhibits a 328 more negative value of $(a-b)$ reaching -0.028 . 
329 For dry samples, we can see that deg10 results are situated between intact and deg25 ones (see 330 Figure $6 \mathrm{a}, \mathrm{c}, \mathrm{e})$. It means that a larger amount of degradation induces a more pronounced 331 velocity-weakening, and this trend is clear for the tests at $0.6,1 \mathrm{MPa}$ of normal stress and the 332 velocity steps $10-33 \mu \mathrm{m} / \mathrm{s}$ at $1.6 \mathrm{MPa}$, but is not visible for the velocity steps $1.7-10 \mu \mathrm{m} / \mathrm{s}$ at 1.6 $333 \mathrm{MPa}$. For the wet experiments, the opposite effect is observed (see Figure $6 \mathrm{~b}$, d, f), the 334 dissolution of the grains leads to coefficients (a-b) that are less negative, even though we still 335 observe a velocity weakening.

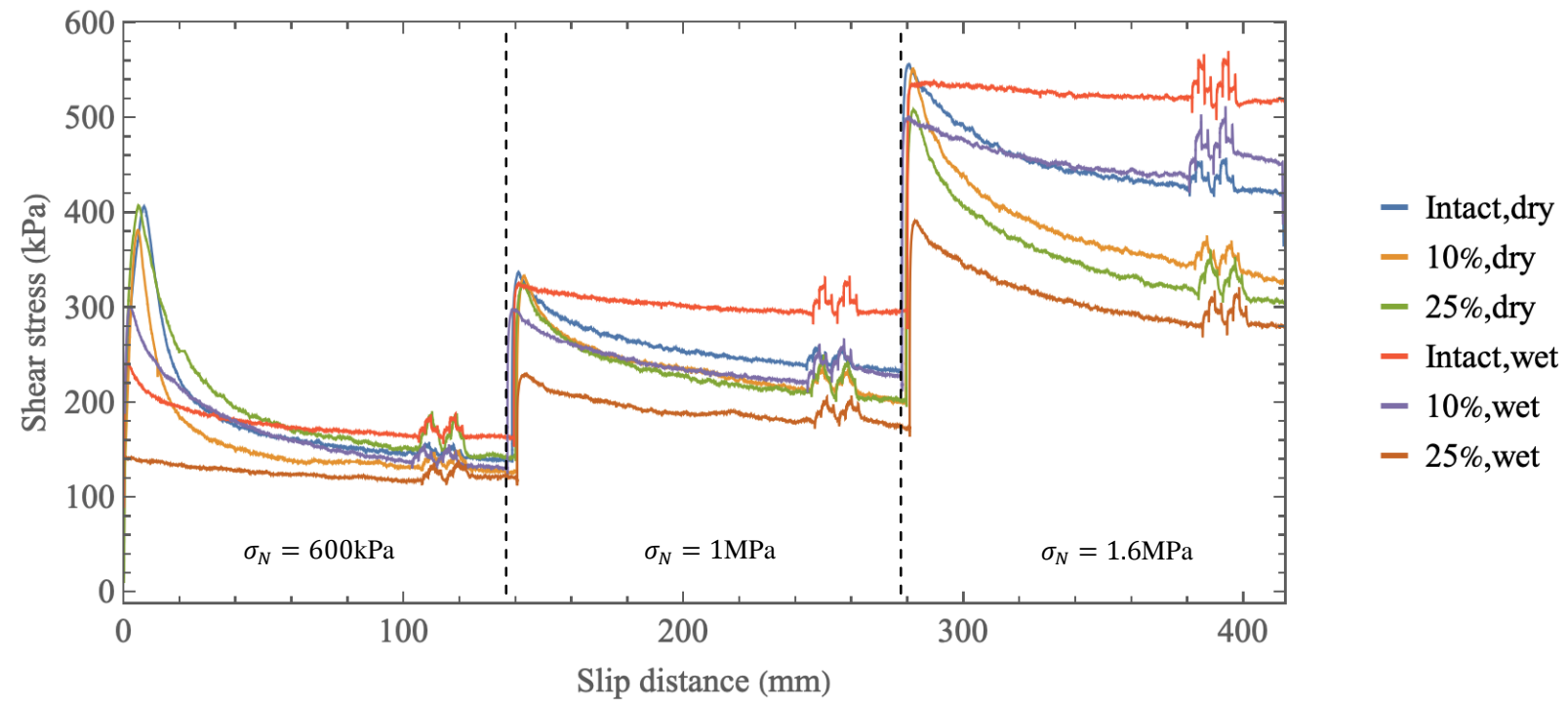

\begin{tabular}{ccccccc}
\hline & \multicolumn{2}{c}{$\mathbf{0 . 6}$ MPa } & \multicolumn{2}{c}{ 1 MPa } & \multicolumn{2}{c}{ 1.6 MPa } \\
\hline & peak & residual & peak & residual & peak & residual \\
\hline intact & 0.67 & 0.24 & 0.34 & 0.24 & 0.35 & 0.26 \\
\hline dissolution 10\% & 0.67 & 0.21 & 0.33 & 0.20 & 0.34 & 0.21 \\
\hline dissolution 25\% & 0.64 & 0.24 & 0.32 & 0.20 & 0.32 & 0.19 \\
\hline Intact, wet & 0.4 & 0.27 & 0.33 & 0.30 & 0.33 & 0.33 \\
\hline dissolution 10\%, wet & 0.5 & 0.22 & 0.3 & 0.23 & 0.31 & 0.29 \\
\hline dissolution 25\%, wet & 0.24 & 0.15 & 0.23 & 0.14 & 0.24 & 0.14
\end{tabular}


343 In Figure 7, the values of the friction parameters $(a-b)$ are plotted as a function of the normal 344 stress for the different degrees of dissolution and velocity steps. The different values obtained for 345 a velocity step are calculated as an average of the values of the velocity jumps involving the 346 same velocity values (velocity jump 10-33 $\mu \mathrm{m} / \mathrm{s}$ : 1-2, 4-5, 5-6, 8-9; velocity jump 1.7-10 $\mu \mathrm{m} / \mathrm{s}$ : $3472-3,3-4,6-7,7-8)$. For the intact gouge, the rate and state parameter $(a-b)$ increase slightly with 348 the normal stress but a more visible dependency on the velocity steps considered is observed. 349 The transition from 10 to $33 \mu \mathrm{m} / \mathrm{s}$ induces more weakening than the transition from 1.7 to 10 $350 \mu \mathrm{m} / \mathrm{s}$. This effect is also observed for the degraded gouge. The dry gouges that underwent $10 \%$ 351 and $25 \%$ dissolution show a distinct increase of the rate and state parameter $(a-b)$ with the 352 normal stress (more pronounced for $25 \%$ dissolution). In these tests, the $(a-b)$ values get closer to 353 zero when the confinement pressure is increased. For the intact sample, $(a-b)$ shows no clear 354 variation with the normal stress. For the wet samples, we also observe a slight increase of $(a-b)$ 355 with the normal stress for the intact sample. However, for the samples with 10 and $25 \%$ 356 degradation, this increase is only observed for the velocity step 10-33 $\mu \mathrm{m} / \mathrm{s}$ and no clear trend is 357 observed for the velocity step 1.7-10 $\mu \mathrm{m} / \mathrm{s}$. It should be noted that the different normal stresses 358 applied here correspond also to larger displacements due to the multi-stage applied to the 359 material, which could affect the evolution of $(a-b)$ observed here. 


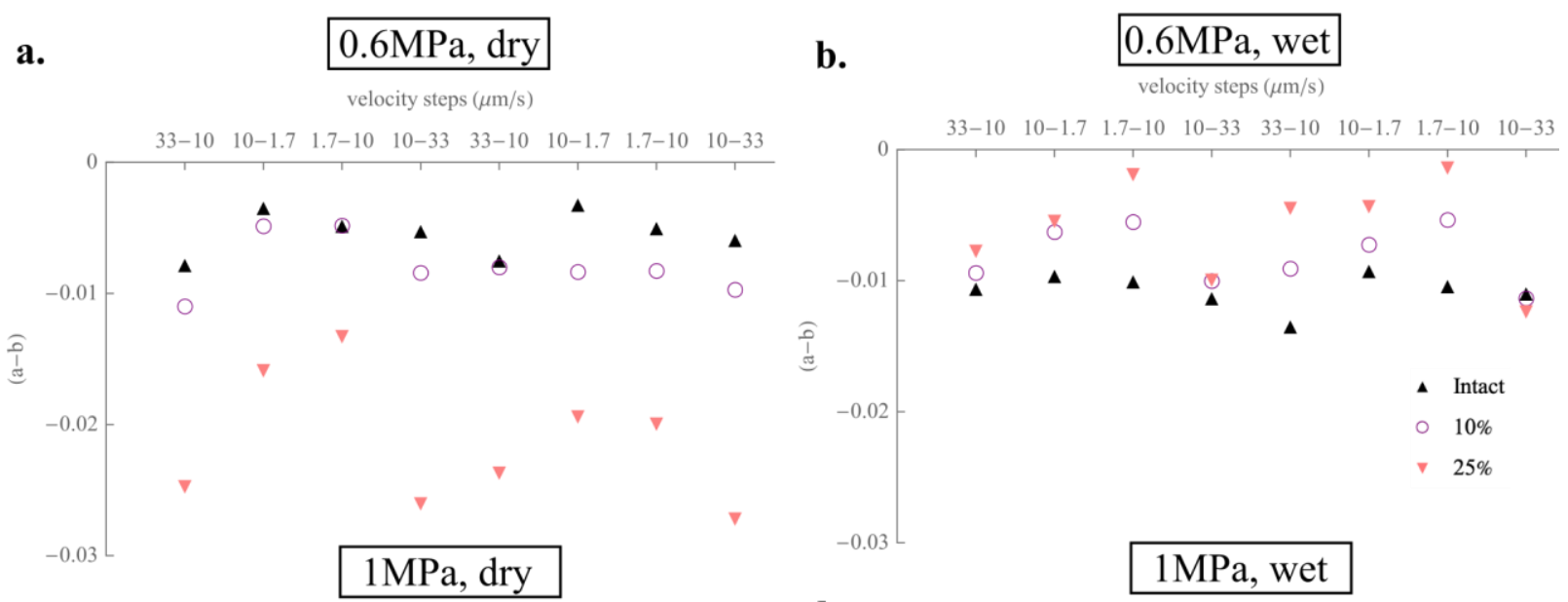

c.

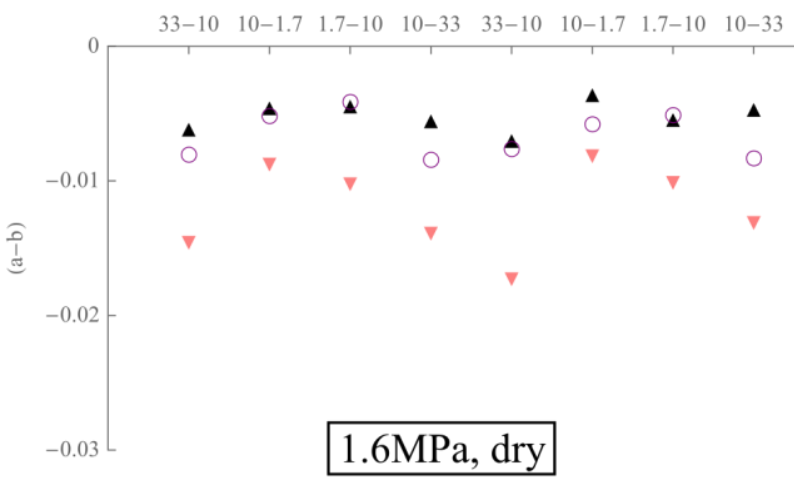

e.

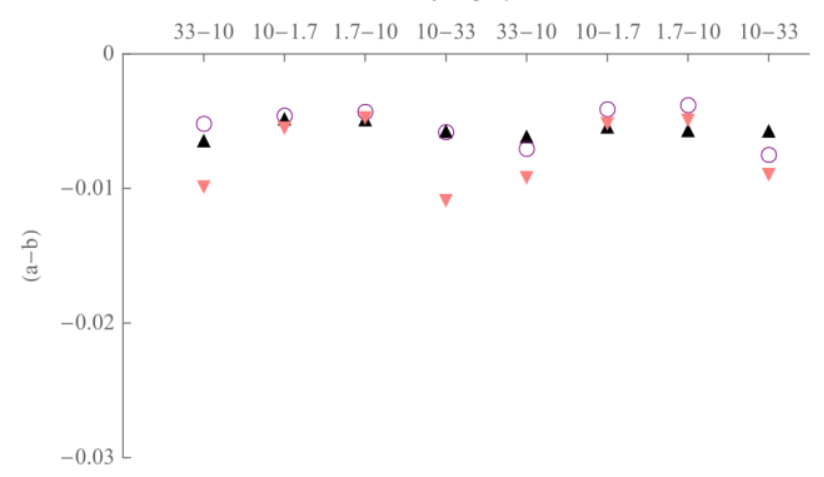

d.

velocity steps $(\mu \mathrm{m} / \mathrm{s})$

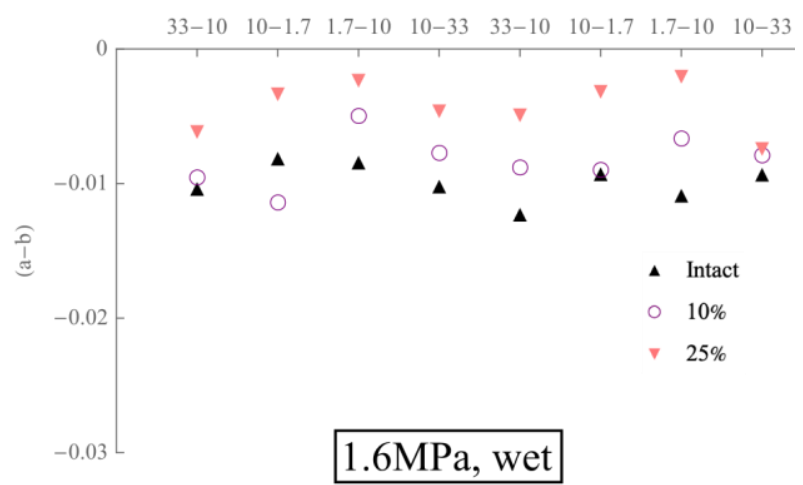

f.

velocity steps $(\mu \mathrm{m} / \mathrm{s})$

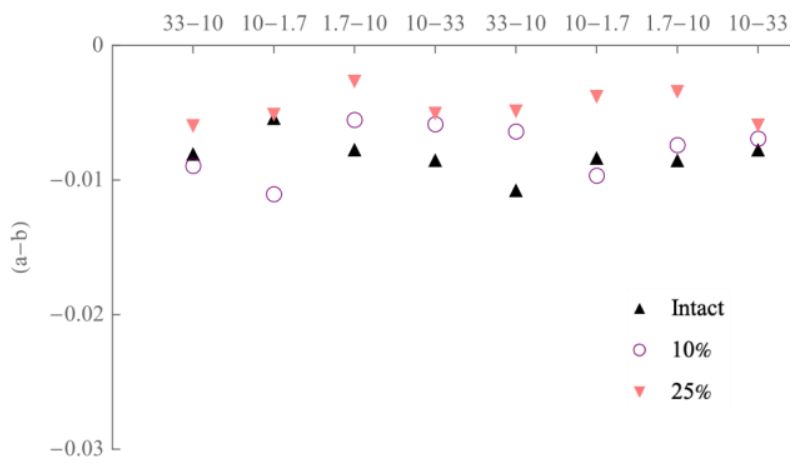

Figure 6. Effect of the dissolution on the rate and state friction parameters $(a-b)$ for the different velocity steps and for different 

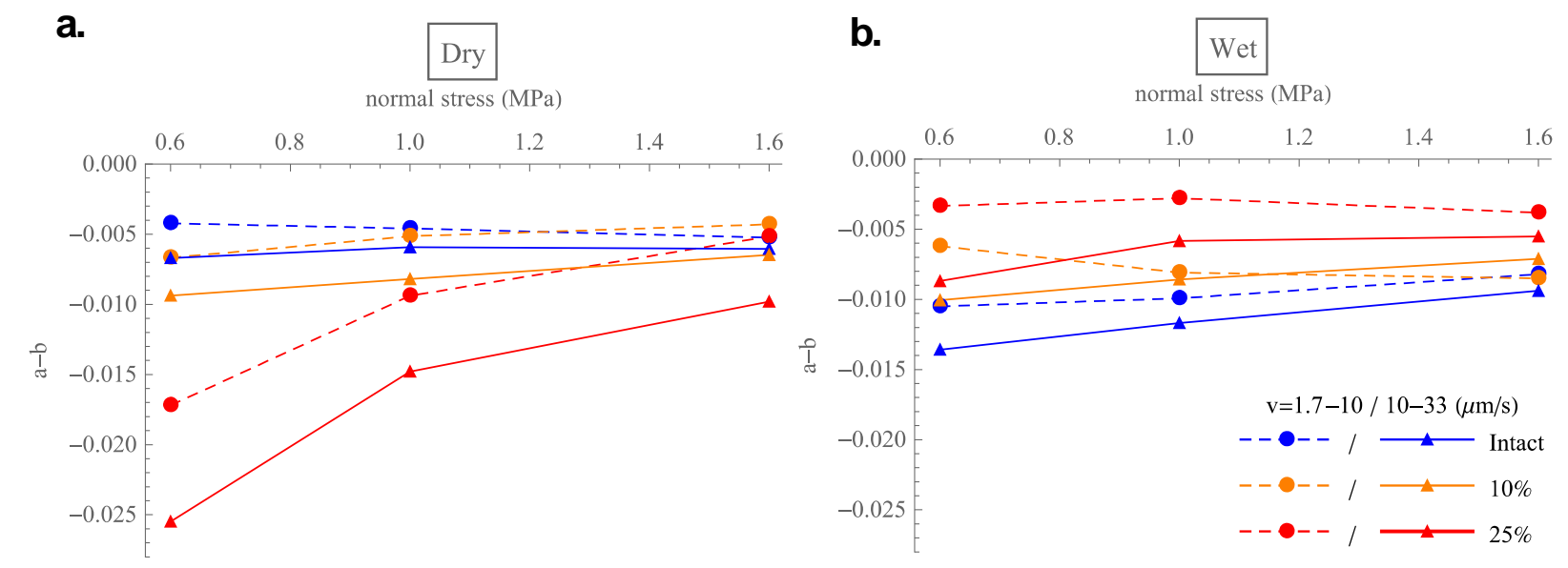

Figure 7. Effect of the normal stress on the rate and state friction parameters (a-b) plotted for the different velocity steps and for different rate of dissolution

\subsection{Roughness of the grains}

367 The dissolution of the calcite through contact with an acid solution before shearing affects not 368 only the grain size distribution but also the shape of the particles. The shape and in particular the 369 roughness of the grains could influence the mechanical response of the sample (Anthony and 370 Marone 2005). Thus, we characterize the roughness and shape of the particles using the specific 371 BET surface area (SA 3100 BET surface area and pore size analyzer; Beckman Coulter, U.S.), 372 sieves analysis and a Scanning Electron Microscope (SEM).

373 The roughness of a given sample is defined as the ratio between the surface areas obtained from 374 the BET method and the particle size analysis (considering spherical particles) as explained in 375 (Micić et al. 2017). The BET method is a way to calculate the specific surface area of a sample 376 based on gas adsorption. Nitrogen is pumped into the sample at a given pressure, with constant 377 temperature (corresponding to the boiling point of liquid Nitrogen) and the adsorption process is 378 measured volumetrically. The isotherm data obtained from this procedure enable to determine 379 the specific surface area based on the theory developed by (Brunauer, Emmett, and Teller 1938) 380 with an accuracy of $0.1 \mathrm{~m}^{2} / \mathrm{g}$. This value of the specific surface area can be compared with one 381 obtained from the particle size distribution (PSD). The latter is obtained by assuming that the 382 mass of material obtained for each size correspond to spherical particles with the diameter of the 383 mesh size (or the size of the volume equivalent for laser diffraction). The results are reported in 384 Table 4. 


\begin{tabular}{cccc}
\hline Sample & $\mathbf{S}_{\mathbf{P S D}}\left(\mathrm{m}^{2} / \mathrm{g}\right)$ & $\mathbf{S}_{\mathbf{B E T}}\left(\mathrm{m}^{2} / \mathrm{g}\right)$ & Roughness \\
\hline Intact & $5.34 \times 10^{-2}$ & 0.96 & 18.03 \\
\hline $\mathbf{1 0 \%}$ & $3.29 \times 10^{-2}$ & 0.83 & 25.32 \\
\hline $\mathbf{2 5 \%}$ & $9.48 \times 10^{-3}$ & 0.99 & 104.32
\end{tabular}

389 The specific surface area obtained from the PSD exhibits a decrease with the amount of 390 dissolution. It is due to the more pronounced dissolution of the small particles that contributes 391 substantially to the value of the specific surface. However, the values obtained from the BET 392 method are not notably affected by the dissolution. Consequently, the roughness increases with 393 the increasing amount of dissolution. (Micić et al. 2017) have performed a similar methodology 394 to evaluate the roughness of different granular materials. They have observed a difference of 395 almost two orders of magnitude for the same definition of the roughness used here between glass 396 beads with a diameter of $1 \mathrm{~mm}$ and Dorsilit8 sand composed of 95\% of quartz presenting 397 moderately well-sorted angular grains $(0.3-0.8 \mathrm{~mm})$, which shows that the difference of the 398 values of roughness reported in Table 4 are reasonable. To understand our results, observations 399 of the grains have been performed using a Variable Pressure Scanning Electron Microscope (FEI 400 XL30 SEM). The specimens have been coated with gold film prior to be placed in the 401 microscope. Images of the intact gouge and the gouge with 25\% degradation are shown in Figure 402 8. The intact gouge exhibits much more fine particles attached to each other or to larger grains 403 than the samples which experienced dissolution. Moreover, grains with a diameter larger than 10 $404 \mu \mathrm{m}$ in the intact gouge (Figure 8. b) present an external surface that exhibits less asperities than 405 the one in the dissolved gouge (Figure 8. d). 
Intact sand
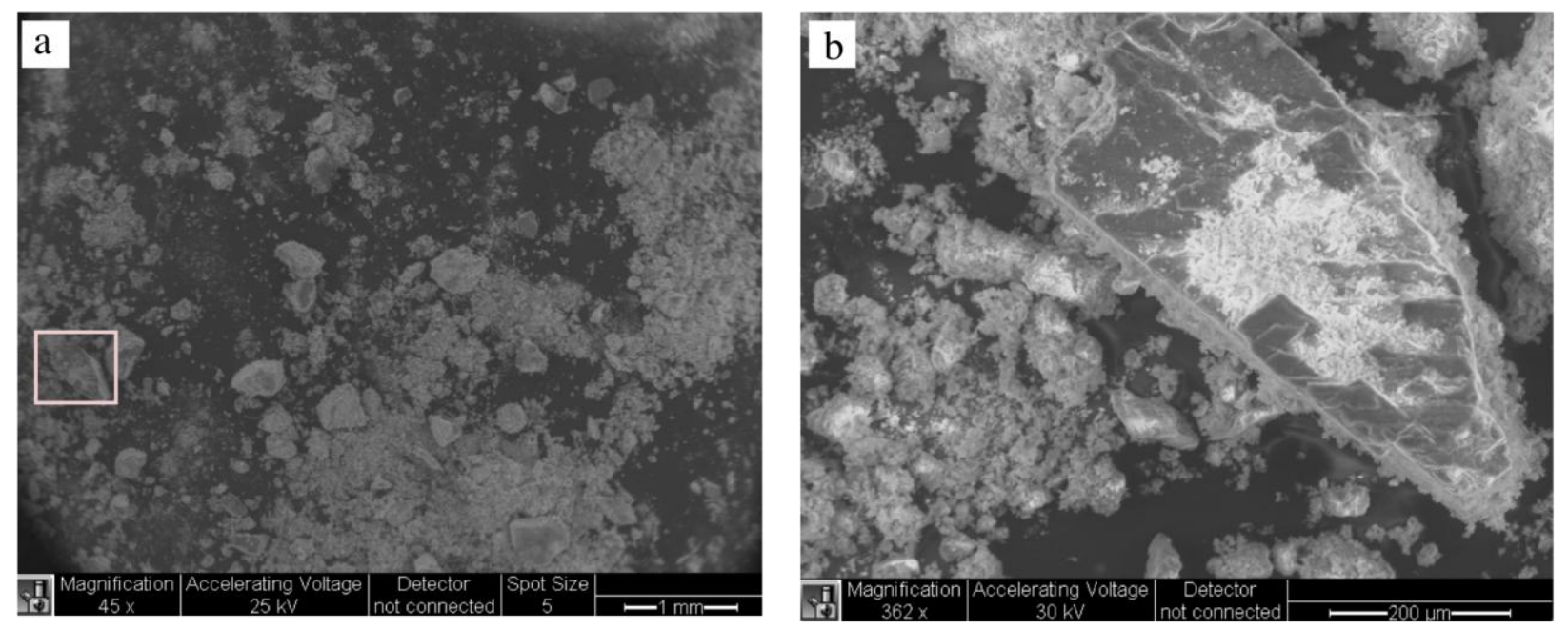

Dissolved sand $25 \%$
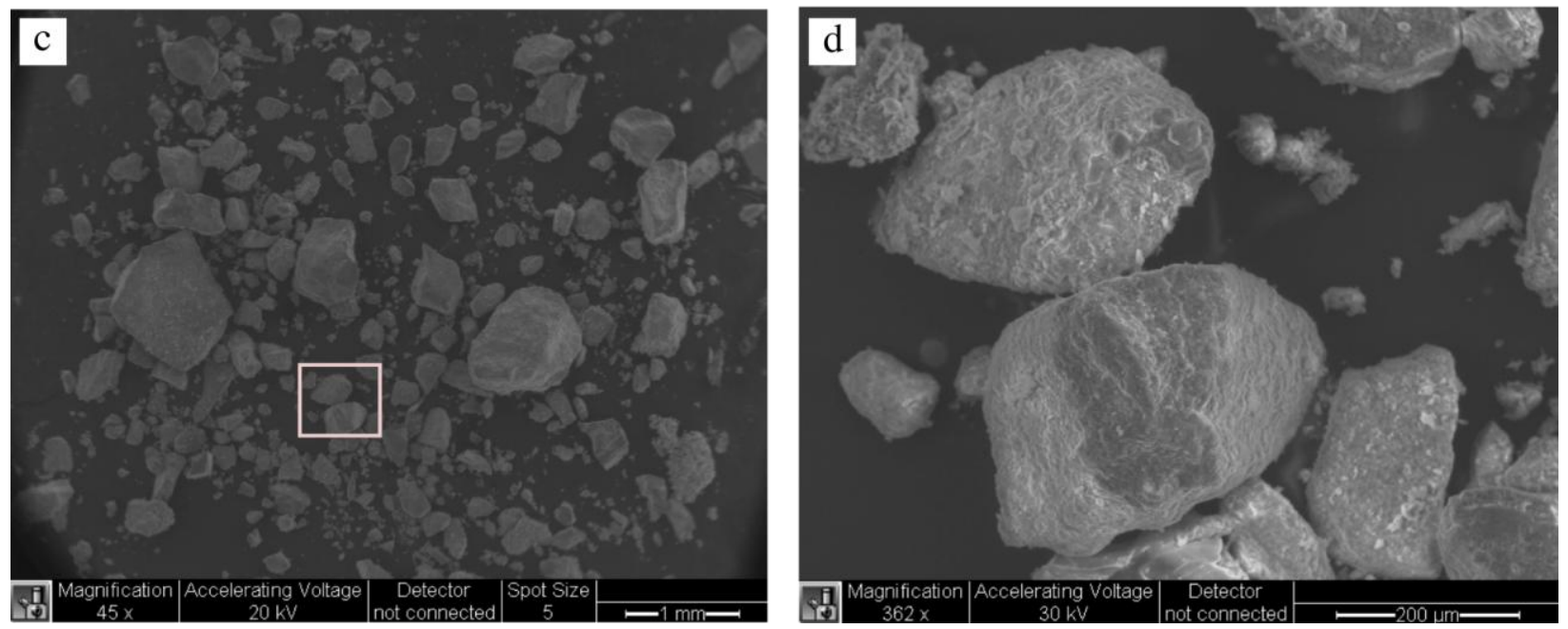

408 Figure 8. Scanning Electron Microscope images of the intact gouge ( $a$ and $b$ ), and the gouge with 25\% dissolution ( $c$ and $d$ ).

\section{4. Discussion}

411 In this section, we integrate the mechanical data from our experiments and microstructural

412 investigation of the gouge prior to shear to discuss the role of the normal stress (see (A. M.H.

413 Pluymakers, Niemeijer, and Spiers 2016b) for a broader discussion on the effect of this

414 parameter), saturation of water and amount of dissolution on the velocity weakening behavior of

415 carbonate bearing faults. We also discuss the implications of our results in the context of

416 injection of an acidic fluid in a reservoir presenting faults composed of carbonates. 


\subsection{Comparison with other works}

418 Our results show that the mechanical behavior of simulated carbonate-bearing faults is

419 modulated by the imposed slip velocity, the normal stress, the amount of chemical dissolution of 420 the grains and the presence of water inside the pores.

421 A number of experimental studies have focused on the frictional behavior of carbonate materials 422 (Han et al. 2007; B. a. Verberne et al. 2013; Smith, Nielsen, and Di Toro 2015; Carpenter et al. 423 2016) under different range of temperature, velocities and normal stress using double direct shear 424 and rotary shear experiments. They observed a strong resistance and a friction coefficient at the 425 peak between 0.6 and 0.7 , consistent with our observations for a normal stress of $600 \mathrm{kPa}$ and 426 sub-seismic velocities. The decrease of the peak friction coefficient in the presence of water has 427 also been previously observed (B. a. Verberne et al. 2013), but the difference was less 428 pronounced than in our observations for the dissolved samples. Moreover, the steady state 429 friction coefficients obtained in experiments reported in the literature stay close to the peak value 430 (at velocities below $1 \mathrm{~cm} / \mathrm{s}$ ), exhibiting thus almost no slip weakening or slip strengthening. This 431 discrepancy is due to the size of the sample used in the ACSA as explained in (Guillaume 432 Chambon, Schmittbuhl, and Corfdir 2006a). This macroscopic slip-weakening operating over 433 centimetric distances is induced by a progressive mechanical decoupling between the interfacial 434 layer and the bulk of the samples, as shown by image analysis during shearing (G. Chambon et 435 al. 2003). This characteristic distance of the slip weakening is much larger than in previous 436 experimental studies and fully consistent with values inferred for large earthquakes (Guillaume 437 Chambon, Schmittbuhl, and Corfdir 2006b).

438 Experiments conducted on gouge at typical velocities consistent with earthquake nucleation (a 439 few micrometers per seconds like here) exhibits velocity strengthening (B. A. Verberne et al. 440 2014) or a velocity neutral (Carpenter et al. 2016) for normal stresses below $20 \mathrm{MPa}$. The order 441 of magnitude of the $(a-b)$ coefficient, we have obtained $\left(10^{-2}\right)$ is in agreement with previous 442 studies on friction in gouge materials composed of quartz or carbonates (Biegel, Sammis, and 443 Dieterich 1989; Carpenter et al. 2016). Nevertheless, our experiments reveal a velocity 444 weakening behavior. This weakening has also been observed by (Guillaume Chambon 2003) for 445 monodisperse quartz sand and glass beads using the annular shear apparatus. The difference in 446 terms of $(a-b)$ can be explained by the large displacements applied to the gouge in our 
447 experiments before the velocity steps compared to experiments performed in double direct shear 448 or saw cut configurations. Large-displacement experiments using a rotary shear apparatus with 449 gouge samples have consistently shown a decrease of the friction rate parameter with 450 displacement and a transition from velocity-strengthening to velocity-weakening (Beeler et al. 451 1996; Marone 1998).

\subsection{Micro-mechanisms affecting the rate and state friction parameters for dry} experiments

454 For the range of normal stresses applied to our samples, the mechanical behavior of the dry 455 gouge is dominated by sliding and rotation of grains, the creation of force chains, cataclasis and 456 strain localization (Anthony and Marone 2005; Guillaume Chambon, Schmittbuhl, and Corfdir

457 2006a; B. a. Verberne et al. 2013). We focus in this section on the possible mechanisms driving 458 the experiments performed for the dry samples and compare with our observations to infer which 459 ones seem to dominate.

460 The dissolution of the calcite by an acid fluid before shearing affects the samples in two ways. 461 First, it generates a modification of the particle size distributions by dissolving preferably the 462 small grains. The fractal number of the distribution decreases and the mean grain size increases. 463 Moreover, the dissolution modifies the roughness of the particles. Both effects can influence the 464 frictional behavior of the sample.

465 (Anthony and Marone 2005) have studied the influence of particle roughness on the frictional 466 behavior of gouge using two materials: spherical glass beads and quartz sand, presenting 467 comparable particle size distributions. They have shown that an decrease of the 468 angularity/roughness of the grains for a similar grain size distribution tends to induce a 469 weakening of the apparent friction coefficient (Anthony and Marone 2005) and the triggering of 470 stick-slip instabilities (manifestation of a more negative rate and state parameter $(a-b)$ ). 471 However, our analysis of the roughness of the particles exhibits an increase with the dissolution 472 but a decrease of the apparent friction (see Figure 5 and Table 4) and a decrease of $(a-b)$ towards 473 more negative values (Figure 6). Therefore, the decrease of the apparent friction and $(a-b)$ with 474 the dissolution for dry experiments cannot be explained as a direct effect of the roughness of the 475 particles. In the present work, the particle size distribution changes (in addition to the roughness 
476 of the grains) when subjected to dissolution, so this effect must dominate the mechanical

477 behavior of the sample and not the modification of the grains' roughness.

478 Compared to silica sand, carbonate sand presents a lower grain hardness and higher intraparticle 479 porosity, which makes them more susceptible to grain crushing (Coop et al. 2004). Recent papers 480 on granular mechanics have linked the rate dependency observed in sand to the crushing of 481 particles (Karimpour and Lade 2010; Y. D. Zhang and Buscarnera 2017; Das and Das 2019). 482 This effect induces a larger compaction rate and thus a stronger velocity-weakening behavior as 483 explained in (Marone 1998). For our experiments, the dissolution affects the width of the particle 484 size distribution and generates a narrower distribution and a higher fraction of large particle. 485 Therefore, the force chains between the grains can be expected to carry a higher load and to be 486 longer (Mair and Hazzard 2007; C. Ovalle et al. 2016). This can lead to a more important 487 comminution process, a decrease of friction and a larger velocity-weakening (a more negative $(a$ 488 b) parameter) as observed here for the dry experiments in Figure 9 and Figure 5. However, the 489 fact that we use multi-stage experiments and large displacements before applying the velocity 490 steps here induces that the velocity steps performed for lower normal stress are performed on a 491 material that is more subject to grain crushing and a larger compaction rate affecting the values 492 of $(a-b)$ obtained.

493 In Figure 7 and Figure 9, the 25\% dry experiments (and also less significantly the 10\% dry) show 494 an increase of the $(a-b)$ parameter with the normal stress. The other tests exhibit only a small 495 variation with the normal stress. This can be attributed to the fact that the experiments with 0.6 496 MPa normal stress are performed on the initial sample (not yet sheared) and the grains can be 497 more subject to grain crushing and thus a higher compaction rate, whereas the tests with higher 498 normal stresses are performed on samples that have already been sheared and thus, the 499 comminution has already modified the PSD. 


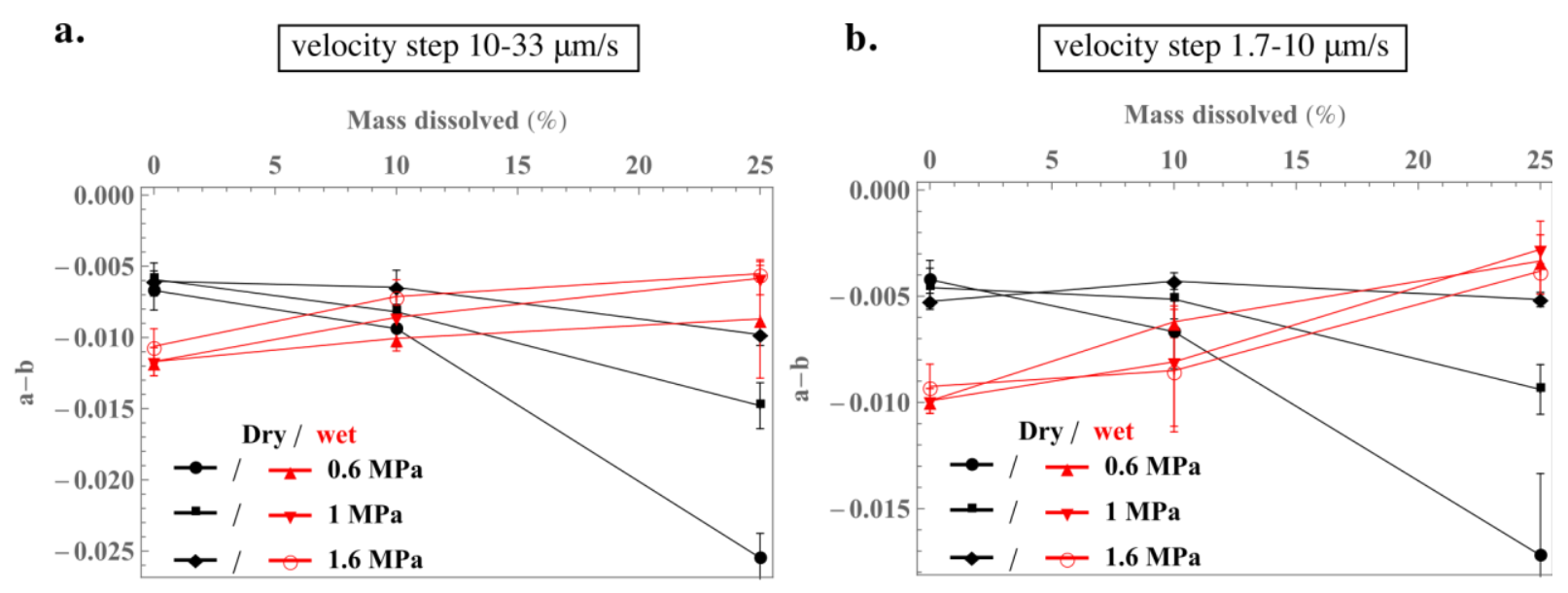

Figure 9. Comparisons of the average (a-b) parameter obtained for a given velocity jump as a function of the amount of

502 dissolution for the wet and dry experiments. Error bars indicate the dispersion of the values of $(a-b)$ between the different steps

503 for the same values of the velocity.

504 Therefore, the mechanical behavior of the dry experiments is inferred to be mainly caused by the grain crushing that is more important for the dissolved samples as the particle size distributions become narrower as it allows to explain the evolution observed for the rate and state parameter $507(a-b)$ and the value of the friction coefficient.

\subsection{Effects of water}

509 In Figure 9, the values of $(a-b)$ for a given step is represented as a function of the percentage of 510 mass dissolved by the acid solution for different normal stresses and in presence or not of water.

511 The different values obtained for a velocity step are calculated as an average of the values of the 512 velocity jumps involving the same velocity values (velocity jump 10-33 $\mu \mathrm{m} / \mathrm{s}$ : 1-2, 4-5, 5-6, 8-9; 513 velocity jump 1.7-10 $\mu \mathrm{m} / \mathrm{s}: 2-3,3-4,6-7,7-8)$. We can observe that the presence of water 514 modifies the influence of the dissolution on the coefficient $(a-b)$. For dry experiments, the 515 dissolution leads to more weakening of the rate parameters towards more negative values, 516 whereas in the wet case it leads to an increase of the rate and state parameter $(a-b)$. Moreover, 517 the addition of water modifies also the value of the friction coefficient at peak and steady state 518 compared to the dry experiments (Figure 5). The peak friction is decreased by the presence of 519 water compared to the dry experiments, however the steady state friction shows a larger value for 520 the intact sample and a lower value in the wet tests compared to the dry tests.

521 As explained in (B. A. Verberne et al. 2014), the effect of unpressurized water is threefold 522 regarding the frictional behavior of granular materials. Water can 1) promote compaction of the 
523 specimen through pressure-solution; 2) lubricate grain contacts; or 3) stimulate cataclasis by 524 lowering the fracture toughness of the grains. The influence of these three mechanisms is 525 discussed in the following paragraphs and compared to our observations to infer which ones 526 dominate during the experiments presented here.

527 The phenomenon of pressure solution is a time-dependent chemo-mechanical process inducing a compaction of rocks and granular assemblies when saturated. It is a dissolution-precipitation 529 mechanism in which the solid is dissolved in stressed regions and precipitates in sheltered 530 regions relatively under-stressed. This process is more active for fine grain materials (Niemeijer, 531 Elsworth, and Marone 2009), and would therefore tend to be more active in the intact gouge than 532 in the dissolved gouges in our case. (X. Zhang and Spiers 2005) performed creep experiments on 533 calcite with normal stresses between 1 and $4 \mathrm{MPa}$ at room temperature and observed most of the 534 deformations induced by pressure solution happened within the first few hours of the 535 experiments. This timescale of pressure solution is similar to the total time of our tests for a 536 similar material and can therefore influence the mechanical behavior. In particular, pressure 537 solution during shearing at low velocities leads to a porosity reduction, an increasing grain contact area (Bos, Peach, and Spiers 2000) and lower absolute value for $(a-b)$ (more neutral)

539 (van den Ende et al. 2018). This phenomenon cannot explain the lower value of ( $a-b)$ for in the 540 wet case compared to the dry for the intact gouge as the slip distances between each velocity 541 jump is too small for it to develop. However, the increased gouge cohesion due to pressure542 solution in wet experiments should lead to a higher steady-state frictional strength than in dry 543 tests as observed in Table 3 for the intact and deg10 experiments, which are samples presenting 544 smaller grains than $\operatorname{deg} 25$ and are therefore more subject to pressure solution. It indicates that 545 this mechanism influences the value of the friction but not the rate and state parameter $(a-b)$ in 546 our experiments.

547 The presence of water promotes grain breakage by decreasing the fracture toughness of 548 individual grains (Atkinson 1982; Carlos Ovalle et al. 2015; Y. Zhang and Buscarnera 2018). 549 This effect is usually referred as subcritical crack propagation and several theories have been 550 developed to explain it based on the modification of the plastic zone near the crack tip or 551 chemical interactions of the water with bonds at the crack tip (Y. Zhang and Buscarnera 2018). 552 This effect induces a larger compaction and thus a stronger velocity-weakening behavior. It can 553 explain the decrease of $(a-b)$ for the intact gouge for the wet compared to the dry experiments 
554 but not the results for the samples submitted to dissolution (in terms of difference wet versus 555 dry). Indeed, carbonate gouges can present a non-self-similar cataclasis and grain crushing is not inhibited when reaching a fractal distribution with fractal number 2.6 and they can exhibit higher fractal numbers than 2.6 (Storti, Billi, and Salvini 2003) compared to silica gouges. Also, the wet 558 intact sample is the only one of the wet experiments showing a small increase of (a-b) with the normal stress, and therefore increasing displacements, for the two velocity steps (Figure 7), which can also be an effect of the grain crushing as the compaction rate decreases with increasing displacements. It should be noted that the effects of water like pressure solution or grain crushing would affect the microstructure of the gouge and therefore the microstructure would not be the same in the dry and wet samples after the initial shear of the material when the velocity steps take place.

565 A third mechanism due to the presence of water is the intergranular lubrication, which decreases intergranular friction and/or adhesion (Cornelio and Violay 2020). This phenomenon leads to a decrease of friction coefficient and an evolution of $(a-b)$ towards neutral velocity dependence in the presence of water compared to the dry case as the effect of changing porosity and thus contact area is less pronounced inducing in this way less velocity weakening (B. A. Verberne et al. 2014). These two effects have been observed for the samples with $25 \%$ mass dissolution (see Table 3 and Figure 9). The intergranular lubrication could be dominant in this case due to the narrower particle size distribution and longer force chains becoming more unstable with the lubrication. Moreover, it can explain the lower friction coefficient at peak for the wet samples 574 compared to the dry ones.

575 Therefore, the above considerations seem to indicate that the frictional behavior of our samples in the presence of water appears to be more controlled by grain breakage/abrasion and pressure

577 solution (for the value of the friction coefficient at steady state) for the intact gouge, and to 578 intergranular lubrication for the degraded gouge (25\%). The behavior of the gouge with $10 \%$ 579 dissolution is not much affected by the presence of water and it is probably a result of the 580 different mechanisms described above competing and counteracting each other. The importance 581 of these mechanisms is inferred to be a result of the narrower particle size distribution and not 582 the change of grains' roughness induced by dissolution. They lead to an increase of the rate and 583 state parameter $(a-b)$ with dissolution for wet gouges, which would decrease the seismic potential of a fault (that are most of the time saturated) by decreasing the critical stiffness under 
which it is unstable (eq. 5). Nonetheless, this complex set of microphysical mechanisms

586 controlling frictional sliding in wet calcite gouges needs to be better constrained using microphysical observations to evaluate the particle size distribution evolution at different stages of the experiments and evidences of the mechanisms operating at the interface between the grains. It will be the subject of future studies.

\subsection{Implications for fault reactivation}

591 Our results can have important implications for the study of $\mathrm{CO}_{2}$ storage or acid gas injection 592 projects, but also to understand the mechanisms of carbonate bearing faults. Indeed, a great 593 number of earthquakes are triggered in such lithologies. Noteworthy examples of seismic slips 594 triggered and propagated through a fault composed of calcite are the magnitude 7.9 Wenchuan 595 (China) earthquake in 2008 (Chen et al. 2013), the magnitude 6.2 Aigion (Greece) earthquake in 5961995 (Bernard et al. 1997), or the magnitude 7.6 Chi-Chi (China) earthquake in 1999 (Boullier et 597 al. 2009). Carbonate rocks are particularly ubiquitous in Italy and in the Apennines where the 598 tectonic activity produce number of seismic events, like in the Amatrice and Norcia areas for the 599 2016-17 seismic sequence (Pizzi et al. 2017), or in L'Aquila for the 2009 earthquake (Valoroso 600 et al. 2014). Moreover, many reservoirs in the world and potential sites for injection of CO2 601 storage or acid gas disposal are composed or carbonate materials (Bjorlykke 2010) and present 602 faults that may induce leakage from the storage if they would be reactivated.

603 Sliding along an existing fault favors grain comminution and abrasion and thus, an increase of 604 the fractal number (Storti, Billi, and Salvini 2003). Our results show that this increase of the 605 fractal number would tend to destabilize the gouge as faults in the crust are located in a wet 606 environment. On the other side, injection of an acid fluid tends to decrease this fractal number by 607 dissolving the small grains. This dissolution decreases the peak friction and promote reactivation 608 but also would reduce the velocity weakening of the fault and could prevent unstable (seismic) 609 slips.

610 In our experiments, the maximum amount of mass decrease due to dissolution of calcite that we 611 have considered is $25 \%$. This high percentage of dissolved mass has been chosen to investigate 612 whether and how dissolution can affect the frictional properties of fault gouges and a lower 613 amount of dissolution would be expected in injection projects. However, (Bakker 2017) have 614 obtained a $25 \%$ decrease of calcite content for a carbonate gouge after 10,000 years of $\mathrm{CO}_{2}$ 
615 injection based on geochemical simulations of the long term effect of $\mathrm{CO}_{2}$ on the mineral 616 composition of a fault gouge, considering a residence time of 1000 years. In this study, the

617 authors considered a carbonate bearing claystone and have investigated the effect of long-term 618 exposure to $\mathrm{CO}_{2}$ on the frictional properties of the fault by changing its mineral composition 619 according to the geochemical model and different scenarios. Therefore, the high percentages of 620 dissolution used in this study could potentially be reached after a long-term injection.

621 However, the experiments presented here have been performed at low normal stresses compared 622 to the stresses applied to faults at seismogenic depths or typical depths of potential $\mathrm{CO}_{2}$ storage 623 sites, which are between at least 800 meters and 5 kilometers depth (Nakanishi et al. 2009), and 624 acid gas injection sites, which are between 700 meters and 5 kilometers depth (Bachu and Gunter 625 2002). This would result in normal stresses between 10 and $100 \mathrm{MPa}$ at the fault and also higher 626 temperatures. The same mechanisms described above are expected to take place at the shallower 627 depths of the faults at these sites (below $50 \mathrm{MPa}$ (Carpenter et al. 2016)), but their relative 628 importance would change. Pressure solution and grain crushing becomes both more important 629 with larger depths and they would have opposite effects on the rate and state parameter $(a-b)$ (an 630 increase for pressure solution and a decrease for grain crushing). On the other side, the viscosity 631 of supercritical $\mathrm{CO}_{2}$ is one tenth the one of water, which would affect grain lubrication and tend 632 to increase $(a-b)$ (Cornelio and Violay 2020). At higher depths, crystal plastic deformation could 633 be triggered and would result in a semi-brittle behavior (Carpenter et al. 2016). Further 634 investigations would be required using an apparatus that allows to apply higher normal stresses 635 to the sample in order to further describe the influence of the different mechanisms at larger 636 depths.

\section{$637 \quad$ 5. Concluding remarks}

638 In this paper, we investigate the effect of the injection of an acid fluid on the frictional properties 639 of a fault located in a carbonate reservoir. The rate and state parameter $(a-b)$ of a simulated 640 calcite gouge are evaluated using an annular shear apparatus and conducting velocity stepping 641 experiments. The material is dissolved using a strong acid prior to mechanical tests in order to 642 investigate the potential effect of weak acids in the long-term. We observe that the long-term 643 exposure to an acid fluid can induce a decrease in the apparent friction and an increase in the rate 644 and state parameter $(a-b)$ for a wet fault by dissolving the small particles and changing the fractal 
645 number of the grain size distribution, whereas dry experiments exhibit a decrease of parameter $646(a-b)$ with dissolution. Our mechanical results are consistent with an interpretation that the 647 frictional behavior of dry samples is controlled by grain breakage, which leads to a velocity 648 weakening when the particles have been exposed to an acid. The presence of water induces 649 different competing mechanisms: it promotes grain breakage and triggers pressure-solution and 650 intergranular lubrication. Here, it is suggested that the dissolution of the grains causes a 651 transition for the frictional behavior to be controlled by grain breakage and pressure-solution to a 652 behavior more influenced by intergranular lubrication. However, the physical processes driving 653 the shear behavior of the granular samples need to be further investigated and constrained from 654 microstructural observations, which will be the focus of future studies. Finally, these 655 experiments enable us to estimate that chemical reactions could potentially induce the 656 reactivation of faults by modifying the grain size distribution and, thus, decreasing the apparent 657 friction but also prevent seismic slip in a storage site by increasing the rate and state parameter $658(a-b)$ of the fault. However, this tendency needs to be confirmed by experiments performed with 659 larger normal stress corresponding to the depths of injection.

\section{Acknowledgments}

662 This work was supported by the French National Research Agency (ANR FISIC n ${ }^{\circ}$ ANR-11663 SEED-0003) and the Southern California Earthquake Center (SCEC), award number 118062196. 664 SCEC is funded by NSF Cooperative Agreement EAR-1033462 and USGS Cooperative 665 Agreement G12AC20038.

\section{References}

Alevizos, S., Thomas Poulet, and Manolis Veveakis. 2014. "Thermo-Poro-Mechanics of Chemically Active Creeping Faults. 1: Theory and Steady State Considerations." Journal of Geophysical Research: Solid Earth, June, n/a-n/a. https://doi.org/10.1002/2013JB010070.

An, Lin Ji, and Charles G. Sammis. 1994. "Particle Size Distribution of Cataclastic Fault Materials from Southern California: A 3-D Study." Pure and Applied Geophysics PAGEOPH 143 (1-3): 203-27. https://doi.org/10.1007/BF00874329. https://doi.org/10.1029/2004JB003399. 
676

677

678

679

680

681

682

683

684

685

686

687

688

689

690

691

692

693

694

695

696

697

698

699

700

701

702

703

704

705

706

707

708

709

710

711

Atkinson, Barry Kean. 1982. "Subcritical Crack Propagation in Rocks: Theory, Experimental Results and Applications." Journal of Structural Geology 4 (1): 41-56. https://doi.org/10.1016/0191-8141(82)90005-0.

Bachu, Stefan, and William D. Gunter. 2002. "Characteristics of Acid Gas Injection Operations in Western Canada. Interim Report to International Energy Agency - Greenhous Gas R\&D Programme."

—. 2004. "Acid-Gas Injection in the Alberta Basin, Canada: A C02-Storage Experience." In Geological Storage of Carbon Dioxid, edited by R. H. BAINES, S. J. \& WORDEN, 22534. Geological Society, London, Special Publications.

Baisch, Stefan, Robert Vörös, Elmar Rothert, Henrik Stang, Reinhard Jung, and Rüdiger Schellschmidt. 2010. "A Numerical Model for Fluid Injection Induced Seismicity at SoultzSous-Forets." International Journal of Rock Mechanics and Mining Sciences 47: 405-13. https://doi.org/10.1016/j.ijrmms.2009.10.001.

Bakker, Elisenda. 2017. "Frictional and Transport Properties of Simulated Faults in CO2 Storage Reservoirs and Clay-Rich Caprocks." Utrecht Series in Earth Sciences №1 24.

Beeler, N. M., T. E. Tullis, M. L. Blanpied, and J. D. Weeks. 1996. "Frictional Behavior of Large Displacement Experimental Faults." Journal of Geophysical Research B: Solid Earth 101 (4): 8697-8715. https://doi.org/10.1029/96jb00411.

Bernard, P, P Briole, B Meyer, H Lyon-Caen, J-M Gomez, C Tiberi, C Berge, et al. 1997. "The Ms=6.2, June 15, 1995 Aigion Earthquake (Greece): Evidence for Low Angle Normal Faulting in the Corinth Rift." Journal of Seismology 1 (2): 131-50.

Biegel, Ronald L., Charles G. Sammis, and James H. Dieterich. 1989. "The Frictional Properties of a Simulated Gouge Having a Fractal Particle Distribution." Journal of Structural Geology 11 (7): 827-46. https://doi.org/10.1016/0191-8141(89)90101-6.

Billi, Andrea. 2005. "Grain Size Distribution and Thickness of Breccia and Gouge Zones from Thin $(<1 \mathrm{~m})$ Strike-Slip Fault Cores in Limestone.” Journal of Structural Geology 27 (10): 1823-37. https://doi.org/10.1016/j.jsg.2005.05.013.

Bjorlykke, Knut. 2010. Petroleum Geoscience: From Sedimentary Enviroments to Rock Physics. Petroleum Geoscience. https://doi.org/10.1007/978-3-642-02332-3.

Blanpied, Michael L., David A. Lockner, and James D. Byerlee. 1995. "Frictional Slip of Granite at Hydrothermal Conditions." Journal of Geophysical Research 100 (B7): 13045-64. https://doi.org/10.1029/95JB00862.

Bos, B, C J Peach, and C J Spiers. 2000. "Frictional-Viscous Flow of Simulated Fault Gouge Caused by the Combined Effects of Phyllosilicates and Pressure Solution." Tectonophysics 327: $173-74$.

Boullier, Anne Marie, En Chao Yeh, Sébastien Boutareaud, Sheng Rong Song, and Chin Ho 
Tsai. 2009. "Microscale Anatomy of the 1999 Chi-Chi Earthquake Fault Zone." Geochemistry, Geophysics, Geosystems 10 (3). https://doi.org/10.1029/2008GC002252.

Brunauer, Stephen, P. H. Emmett, and Edward Teller. 1938. "Adsorption of Gases in Multimolecular Layers." Journal of the American Chemical Society 60 (2): 309-19. https://doi.org/citeulike-article-id:4074706.

Cappa, Frederic. 2012. "Impact of CO2 Geological Sequestration on the Nucleation of Earthquakes." Geophysical Research Letters, 38, L17313, 2011, September. http://escholarship.org/uc/item/15f9x6mp\#page-12.

Carpenter, B M, C Collettini, C Viti, and A Cavallo. 2016. "The Influence of Normal Stress and Sliding Velocity on the Frictional Behaviour of Calcite at Room Temperature: Insights from Laboratory Experiments and Microstructural Observations." Geophysical Journal International 205 (1): 548-61. https://doi.org/10.1093/gji/ggw038.

Chambon, G., J. Schmittbuhl, A. Corfdir, J. P. Vilotte, and S. Roux. 2003. "Shear with Comminution of a Granular Material: Microscopic Deformations Outside the Shear Band." Physical Review E - Statistical Physics, Plasmas, Fluids, and Related Interdisciplinary Topics 68 (1): 8. https://doi.org/10.1103/PhysRevE.68.011304.

Chambon, Guillaume. 2003. "Caractérisation Expérimentale Du Frottement Effectif Des Zones de Faille." École Nationale des Ponts et Chaussées. http://tel.archives-ouvertes.fr/tel00006613/.

Chambon, Guillaume, Jean Schmittbuhl, and Alain Corfdir. 2006a. "Frictional Response of a Thick Gouge Sample: 1. Mechanical Measurements and Microstructures." Journal of Geophysical Research: Solid Earth 111 (9): 1-17. https://doi.org/10.1029/2003JB002731.

- 2006b. "Frictional Response of a Thick Gouge Sample: 2. Friction Law and Implications for Faults." Journal of Geophysical Research: Solid Earth 111 (9): 1-12. https://doi.org/10.1029/2004JB003339.

Chen, Jianye, Xiaosong Yang, Shengli Ma, and Christopher J Spiers. 2013. "Mass Removal and Clay Mineral Dehydration/Rehydration in Carbonate-Rich Surface Exposures of the 2008 Wenchuan Earthquake Fault: Geochemical Evidence and Implications for Fault Zone Evolution and Coseismic Slip." Journal of Geophysical Research: Solid Earth 118 (2): 474-96. https://doi.org/10.1002/jgrb.50089.

Coop, M. R., K. K. Sorensen, T. Bodas Freitas, and G. Georgoutsos. 2004. "Particle Breakage during Shearing of a Carbonate Sand." Geotechnique 54 (3): 157-63. https://doi.org/10.1680/geot.2004.54.3.157.

Corfdir, Alain, Patrick Lerat, and Ioannis Vardoulakis. 2004. "A Cylinder Shear Apparatus." Geotechnical Testing Journal 27 (5): 447-55. https://doi.org/10.1520/gtj11551.

Cornelio, Chiara, and Marie Violay. 2020. "Effect of Fluid Viscosity on Earthquake Nucleation." Geophysical Research Letters 47: 1-9. https://doi.org/10.1029/2020GL087854. 
Das, Soukat Kumar, and Arghya Das. 2019. "Influence of Quasi-Static Loading Rates on Crushable Granular Materials: A DEM Analysis." Powder Technology 344 (January 2019): 393-403. https://doi.org/10.1016/j.powtec.2018.12.024.

Dieterich, James H. 1979. "Modeling of Rock Friction: 1. Experimental Results and Constitutive Equations." Journal of Geophysical Research $84 \quad$ (B5): 2161. https://doi.org/10.1029/JB084iB05p02161.

—. 1981. "Constitutive Properties of Faults with Simulated Gouge." Geophysical Monograph Series 103-20. http://www.agu.org/books/gm/v024/GM024p0103/GM024p0103.shtml.

Ellsworth, William L. 2013. “Injection-Induced Earthquakes.” Science 341 (July): 1-8.

Ende, M. P.A. van den, J. Chen, J. P. Ampuero, and A. R. Niemeijer. 2018. “A Comparison between Rate-and-State Friction and Microphysical Models, Based on Numerical Simulations of Fault Slip." Tectonophysics 733 (July 2017): 273-95. https://doi.org/10.1016/j.tecto.2017.11.040.

Espinoza, D Nicolas. 2011. "Carbon Geological Storage - Underlying Phenomena and Implications -."

Foulger, Gillian R, Miles P Wilson, Jon G Gluyas, Bruce R Julian, and Richard J Davies. 2018. "Global Review of Human-Induced Earthquakes." Earth-Science Reviews 178 (July 2017): 438-514. https://doi.org/10.1016/j.earscirev.2017.07.008.

Han, Raehee, Toshihiko Shimamoto, T Hirose, J H Ree, and J Ando. 2007. "Ultralow Friction of Carbonate Faults Caused by Thermal Decomposition." Science 316 (5826): 878-81. https://doi.org/10.1126/science.1139763.

Karimpour, Hamid, and Poul V. Lade. 2010. "Time Effects Relate to Crushing in Sand." Journal of Geotechnical and Geoenvironmental Engineering 136 (9): 1209-19. https://doi.org/10.1061/(ASCE)GT.1943-5606.0000335.

Khan, Chawarwan, Robert Amin, and Gary Madden. 2013. "Effects of CO2 and Acid Gas Injection on Enhanced Gas Recovery and Storage." Journal of Petroleum Exploration and Production Technology 3 (1): 55-60. https://doi.org/10.1007/s13202-012-0044-8.

Kirk-Othmer. 2004. Kirk-Othmer Encyclopedia of Chemical Technology, Volume 4. Edited by Kirk-Othmer. 2004th ed. Hoboken, NJ: Wiley.

Koval, Georg, François Chevoir, Jean-Noël Roux, Jean Sulem, and Alain Corfdir. 2011. "Interface Roughness Effect on Slow Cyclic Annular Shear of Granular Materials." Granular Matter 13 (5): 525-40. https://doi.org/10.1007/s10035-011-0267-2.

Lund, Kasper, H. S. Fogler, C. C. McCune, and J. W. Ault. 1975. "Acidization-II. The Dissolution of Calcite in Hydrochloric Acid." Chemical Engineering Science 30 (8): 82535. https://doi.org/10.1016/0009-2509(75)80047-9. 
Mair, Karen, and James F. Hazzard. 2007. "Nature of Stress Accommodation in Sheared Granular Material: Insights from 3D Numerical Modeling." Earth and Planetary Science Letters 259 (3-4): 469-85. https://doi.org/10.1016/j.eps1.2007.05.006.

Marone, Chris J. 1998. "Laboratory-Derived Friction Laws and Their Application To Seismic Faulting." Annual Review of Earth and Planetary Sciences 26 (1): 643-96. https://doi.org/10.1146/annurev.earth.26.1.643.

Messen, Y. H., A. Corfdir, and J. Schmittbuhl. 2013. "Mechanical Healing of Simulated Fault Gouge." Geophysical Journal International $193 \quad$ (1): 252-62. https://doi.org/10.1093/gji/ggs082.

Michael, K., A. Golab, V. Shulakova, J. Ennis-King, G. Allinson, S. Sharma, and T. Aiken. 2010. "Geological Storage of CO2 in Saline Aquifers-A Review of the Experience from Existing Storage Operations." International Journal of Greenhouse Gas Control 4 (4): 65967. https://doi.org/10.1016/j.ijggc.2009.12.011.

Micić, Vesna, Doris Schmid, Nathan Bossa, Andreas Gondikas, Milica Velimirovic, Frank Von Der Kammer, Mark R. Wiesner, and Thilo Hofmann. 2017. "Impact of Sodium Humate Coating on Collector Surfaces on Deposition of Polymer-Coated Nanoiron Particles." Environmental Science and Technology 51 (16): 9202-9. https://doi.org/10.1021/acs.est.7b01224.

Mortezaei, Kimia, and Farshid Vahedifard. 2015. "Numerical Simulation of Induced Seismicity in Carbon Capture and Storage Projects." Geotechnical and Geological Engineering 33 (2): 411-24. https://doi.org/10.1007/s10706-015-9859-7.

Nakanishi, Shigetaka, Yasunobu Mizuno, Tadahiko Okumura, Hideaki Miida, Takumi Shidahara, and Shin-ichi Hiramatsu. 2009. "Methodology of CO2 Aquifer Storage Capacity Assessment in Japan and Overview of the Project." Energy Procedia 1 (1): 2639-46. https://doi.org/10.1016/j.egypro.2009.02.031.

Niemeijer, André, Derek Elsworth, and Chris Marone. 2009. "Significant Effect of Grain Size Distribution on Compaction Rates in Granular Aggregates." Earth and Planetary Science Letters 284 (3-4): 386-91. https://doi.org/10.1016/j.epsl.2009.04.041.

Ovalle, C., C. Voivret, C. Dano, and P.-Y. Hicher. 2016. "Population Balance in Confined Comminution Using a Physically Based Probabilistic Approach for Polydisperse Granular Materials." International Journal for Numerical and Analytical Methods in Geomechanics 40: 2383-2397. https://doi.org/10.1002/nag.

Ovalle, Carlos, Christophe Dano, Pierre Yves Hicher, and Mónica Cisternas. 2015. "Experimental Framework for Evaluating the Mechanical Behavior of Dry and Wet Crushable Granular Materials Based on the Particle Breakage Ratio." Canadian Geotechnical Journal 52 (5): 587-98. https://doi.org/10.1139/cgj-2014-0079.

Pizzi, A., A. Di Domenica, F. Gallovic, L. Luzi, and R. Puglia. 2017. "Fault Segmentation as Constraint to the Occurrence of the Main Shocks of the 2016 Central Italy Seismic 
Sequence.” Tectonics 36 (11): 2370-87. https://doi.org/10.1002/2017TC004652.

Pluymakers, A. M.H., A. R. Niemeijer, and C. J. Spiers. 2016a. "Frictional Properties of Simulated Anhydrite-Dolomite Fault Gouge and Implications for Seismogenic Potential." Journal of Structural Geology 84: 31-46. https://doi.org/10.1016/j.jsg.2015.11.008.

- 2016b. "Frictional Properties of Simulated Anhydrite-Dolomite Fault Gouge and Implications for Seismogenic Potential." Journal of Structural Geology. https://doi.org/10.1016/j.jsg.2015.11.008.

Pluymakers, Anne M H, Jon E Samuelson, André R Niemeijer, and Christopher J Spiers. 2014. "Effects of Temperature and $\mathrm{CO} 2$ on the Frictional Behavior of Simulated Anhydrite Fault Rock." Journal of Geophysical Research: Solid Earth 119,: 8728-8747. https://doi.org/10.1002/2014JB011575.Received.

Rattez, Hadrien, Ioannis Stefanou, and Jean Sulem. 2018. "The Importance of Thermo-HydroMechanical Couplings and Microstructure to Strain Localization in 3D Continua with Application to Seismic Faults. Part I: Theory and Linear Stability Analysis." Journal of the Mechanics and Physics of Solids 115: 54-76. https://doi.org/10.1016/j.jmps.2018.03.004.

Rattez, Hadrien, Ioannis Stefanou, Jean Sulem, Manolis Veveakis, and Thomas Poulet. 2018. "The Importance of Thermo-Hydro-Mechanical Couplings and Microstructure to Strain Localization in 3D Continua with Application to Seismic Faults . Part II : Numerical Implementation and Post-Bifurcation Analysis." Journal of the Mechanics and Physics of Solids 115: 1-29. https://doi.org/10.1016/j.jmps.2018.03.003.

Rattez, Hadrien, Ioannis Stefanou, Manolis Veveakis, Thomas Poulet, and Jean Sulem. 2018. "Numerical Analysis of Strain Localization in Rocks with THM Couplings: Benchmark Tests and Microstructure." Rock Mechanics and Rock Engineering.

Rattez, Hadrien, Jean Sulem, and Siavash Ghabezloo. 2014. "Effect of CO2 on Fault Friction and Slip Stability." In 25th ALERT Workshop, Aussois, France.

Rattez, Hadrien, and Manolis Veveakis. 2020. "Weak Phases Production and Heat Generation Control Fault Friction during Seismic Slip." Nature Communications 11 (350). https://doi.org/10.1038/s41467-019-14252-5.

Reid, Harry F. 1910. “The Mechanism of the Earthquake.” In The California Earthquake of April 18, 1906, Report of the State Earthquake Investigation Commision, Vol. 2, 1-192.

Rice, James R. 2006. "Heating and Weakening of Faults during Earthquake Slip." Journal of Geophysical Research: Solid Earth 111 (5). https://doi.org/10.1029/2005JB004006.

Rice, James R., and A Ruina. 1983. "Stability of Steady Frictional Slipping." Journal of Applied Mechanics 50 (2): 343. https://doi.org/10.1115/1.3167042.

Rohmer, J., A. Pluymakers, and F. Renard. 2016. "Mechano-Chemical Interactions in Sedimentary Rocks in the Context of CO2 Storage: Weak Acid, Weak Effects?" Earth- 
Science Reviews 157 (June 2016): 86-110. https://doi.org/10.1016/j.earscirev.2016.03.009.

860 Rubinstein, Justin L., and Alireza Babaie Mahani. 2015. "Myths and Facts on Wastewater Injection, Hydraulic Fracturing, Enhanced Oil Recovery, and Induced Seismicity." Seismological Research Letters 86 (4): 1060-67. https://doi.org/10.1785/0220150067.

Ruina, A. 1983. "Slip Instability and State Variable Friction Laws." Journal of Geophysical

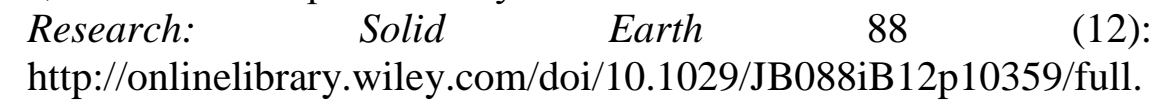

Sammis, Charles G., Geoffrey King, and Ronald L. Biegel. 1987. "The Kinematics of Gouge Deformation." Pure and Applied Geophysics 125 (5): 777-812. https://doi.org/10.1007/BF00878033.

Samuelson, Jon E, and Christopher J Spiers. 2012. "Fault Friction and Slip Stability Not Affected by CO2 Storage : Evidence from Short-Term Laboratory Experiments on North Sea Reservoir Sandstones and Caprocks." International Journal of Greenhouse Gas Control Volume 11 (November 2012): 78-90.

Schoenball, Martin, and William Ellsworth. 2017. "A Systematic Assessment of the Spatiotemporal Evolution of Fault Activation Through Induced Seismicity in Oklahoma and Southern Kansas." Journal of Geophysical Research : Solid Earth 122 (12): 10,189-10,206. https://doi.org/10.1002/2017JB014850.

Scholz, Christopher H. 1998. "Earthquakes and Friction Laws.” Nature 391 (January 1998): $37-$ 42.

Scuderi, Marco M., André R Niemeijer, Cristiano Collettini, and Chris J. Marone. 2013. "Frictional Properties and Slip Stability of Active Faults within Carbonate-Evaporite Sequences: The Role of Dolomite and Anhydrite." Earth and Planetary Science Letters 369-370 (May): 220-32. https://doi.org/10.1016/j.epsl.2013.03.024.

Smith, Steven A. F., Stefan Nielsen, and Giulio Di Toro. 2015. "Strain Localization and the Onset of Dynamic Weakening in Calcite Fault Gouge." Earth and Planetary Science Letters 413 (March): 25-36. https://doi.org/10.1016/j.epsl.2014.12.043.

Steacy, S J, and C G Sammis. 1991. "An Automaton for Fractal Patterns of Fragmentation." Nature 353 (6341): 250-52. https://doi.org/10.1038/353250a0.

Storti, Fabrizio, Andrea Billi, and Francesco Salvini. 2003. "Particle Size Distributions in Natural Carbonate Fault Rocks: Insights for Non-Self-Similar Cataclasis." Earth and Planetary Science Letters 206: 173-86.

Sulem, Jean, and V Famin. 2009. "Thermal Decomposition of Carbonates in Fault Zones: SlipWeakening and Temperature-Limiting Effects." Journal of Geophysical Research 114 (B3): 1-14. https://doi.org/10.1029/2008JB006004.

Tembe, Sheryl, David A. Lockner, and Teng Fong Wong. 2010. "Effect of Clay Content and 
Mineralogy on Frictional Sliding Behavior of Simulated Gouges: Binary and Ternary Mixtures of Quartz, Illite, and Montmorillonite." Journal of Geophysical Research: Solid Earth 115 (3): 1-22. https://doi.org/10.1029/2009JB006383.

Torabi, A., M. U. Johannessen, and T. S. S. Ellingsen. 2019. "Fault Core Thickness: Insights from Siliciclastic and Carbonate Rocks." Geofluids 2019: 1-24. https://doi.org/10.1155/2019/2918673.

Unterreiner, P., P. Lerat, I. Vardoulakis, F. Schlosser, E. De Laure, and G. Belmont. 1993. Brevet sur l'Appareil de Cisaillement Simple Annulaire (ACSA), issued 1993.

Valoroso, Luisa, Lauro Chiaraluce, Cristiano Collettini, Istituto Nazionale, Vigna Murata, Dipartimento Scienze, Sapienza Università, and Piazzale Aldo Moro. 2014. "Earthquakes and Fault Zone Structure." Geology 42 (4): 343-46. https://doi.org/10.1130/G35071.1.

Verberne, B. a., Christopher J Spiers, a. R. Niemeijer, J. H. P. Bresser, D. a. M. Winter, and O. Plümper. 2013. "Frictional Properties and Microstructure of Calcite-Rich Fault Gouges Sheared at Sub-Seismic Sliding Velocities." Pure and Applied Geophysics, December. https://doi.org/10.1007/s00024-013-0760-0.

Verberne, B. A., Christopher J Spiers, André R Niemeijer, J. H P De Bresser, D. A M De Winter, and O. Plümper. 2014. "Frictional Properties and Microstructure of Calcite-Rich Fault Gouges Sheared at Sub-Seismic Sliding Velocities." Pure and Applied Geophysics 171 (10): 2617-40. https://doi.org/10.1007/s00024-013-0760-0.

Verberne, Berend A., André R. Niemeijer, Johannes H.P. De Bresser, and Christopher J. Spiers. 2015. "Mechanical Behavior and Microstructure of Simulated Calcite Fault Gouge Sheared at $20-600^{\circ} \mathrm{C}$ : Implications for Natural Faults in Limestones." Journal of Geophysical Research: Solid Earth 120: 8169-96. https://doi.org/10.1002/2015JB012292.Received.

Veveakis, Manolis, Thomas Poulet, and S. Alevizos. 2014. "Thermo-Poro-Mechanics of Chemically Active Creeping Faults: 2. Transient Considerations." Journal of Geophysical Research: Solid Earth 119 (6): 4583-4605. https://doi.org/10.1002/2013JB010071.

Wilson, M. P., G. R. Foulger, J. G. Gluyas, R. J. Davies, and B. R. Julian. 2017. "HiQuake: The Human- Induced Earthquake Database.” Seismological Research Letters 88 (6): 1560-65. https://doi.org/10.1785/0220170112.

Yehya, Alissar, Zhuo Yang, and James Robert Rice. 2018. "Effect of Fault Architecture and Permeability Evolution on Response to Fluid Injection." Journal of Geophysical Research: Solid Earth 123 (11): 9982-97. https://doi.org/10.1029/2018JB016550.

Zhang, X., and C. J. Spiers. 2005. "Compaction of Granular Calcite by Pressure Solution at Room Temperature and Effects of Pore Fluid Chemistry." International Journal of Rock Mechanics and Mining Sciences 42: 950-60. https://doi.org/10.1016/j.ijrmms.2005.05.017.

Zhang, Y. D., and G. Buscarnera. 2017. "A Rate-Dependent Breakage Model Based on the Kinetics of Crack Growth at the Grain Scale." Géotechnique 67 (11): 953-67. 
932 https://doi.org/10.1680/jgeot.16.p.181.

933 Zhang, Yida, and Giuseppe Buscarnera. 2018. "Breakage Mechanics for Granular Materials in $934 \quad$ Surface-Reactive Environments." Journal of the Mechanics and Physics of Solids 112: 89935 108. https://doi.org/10.1016/j.jmps.2017.11.008.

936 